\title{
Research Article \\ Basel III and the Net Stable Funding Ratio
}

\author{
F. Gideon, ${ }^{1}$ Mark A. Petersen, ${ }^{2}{\text { Janine Mukuddem-Petersen, }{ }^{3} \text { and LNP Hlatshwayo }}^{3}$ \\ ${ }^{1}$ Department of Mathematics, Faculty of Science, University of Namibia, Private Bag 13301, Windhoek 9000, Namibia \\ ${ }^{2}$ Research Division, Faculty of Commerce and Administration, North-West University, Private Bag x2046, \\ Mmabatho 2735, South Africa \\ ${ }^{3}$ Economics Division, Faculty of Commerce and Administration, North-West University, Private Bag x2046, \\ Mmabatho 2735, South Africa \\ Correspondence should be addressed to F. Gideon; fgideon@unam.na
}

Received 28 September 2012; Accepted 15 November 2012

Academic Editors: S.-W. Chyuan, Y. Wang, and Y.-G. Zhao

Copyright (C) 2013 F. Gideon et al. This is an open access article distributed under the Creative Commons Attribution License, which permits unrestricted use, distribution, and reproduction in any medium, provided the original work is properly cited.

\begin{abstract}
We validate the new Basel liquidity standards as encapsulated by the net stable funding ratio in a quantitative manner. In this regard, we consider the dynamics of inverse net stable funding ratio as a measure to quantify the bank's prospects for a stable funding over a period of a year. In essence, this justifies how Basel III liquidity standards can be effectively implemented in mitigating liquidity problems. We also discuss various classes of available stable funding and required stable funding. Furthermore, we discuss an optimal control problem for a continuous-time inverse net stable funding ratio. In particular, we make optimal choices for the inverse net stable funding targets in order to formulate its cost. This is normally done by obtaining analytic solution of the value function. Finally, we provide a numerical example for the dynamics of the inverse net stable funding ratio to identify trends in which banks behavior convey forward looking information on long-term market liquidity developments.
\end{abstract}

\section{Introduction}

The episode of financial market turbulence in 2007-2009 has depicted the importance of liquidity for normal functioning of the financial system. It is because of this background that we are contributing to the procedures for the regulation and supervision of sound liquidity risk management for banks. Some of the well-documented materials to this regard are the notable papers by [1-4]. The Basel Committee on Banking Supervision (BCBS) outlines certain measures to strengthen global capital and liquidity regulations. The objective for these measures is to improve the banking sector's ability to ensure that risk does not spillover to the real economy. The measures are formulated in a form of a principle for sound liquidity risk management and supervision comprising quantitative and qualitative management instruments (see, e.g., [1]). In essence, the response provides guidance on risk management and supervision for funding liquidity risk and promotes a better risk management in that critical area of financial segment. As such, the committee will coordinate rigorous followup by supervisors to ensure that banks adhere to these fundamentals principles (see [3] for more details).
The global economic crisis which recently attack the financial system occurs due to liquidity constraints. We define liquidity constraint as an arbitrary limit on the amount an individual can borrow or an arbitrary alteration in the interest rate they pay. In some instances banks exchange assets in the form of collateral in order to have access to finances. In essence, pledgeable assets support more borrowing which further influence more investment. That is, the financial frictions affect corporate investment (see, e.g., [5] for more information) in which tangible bank assets increase their potential to access external fundings. This is because we expect tangible assets to mitigate the contractibility problems in which the value borrowed could be captured by creditors in default states. In the end, one would expect that financial frictions which affect investment decisions in which tangibility has no effect on the cash flow sensitivities of financially unconstrained bank.

Several investors are facing economic challenges from the bigger market players who have access to overseas finances. The BCBS established two important standards to compliment the principle for sound liquidity risk management and 
supervision. The two standards are expected to achieve some financial objectives. In the first instance, the objective is to promote short-term resilience of a bank's liquidity risk profile by ensuring that the bank has sufficient high-quality liquid assets which is achieved through liquidity coverage ratio (LCR) analysis. The LCR is given as a ratio of the value of the stock of high-quality liquid assets in stressed conditions to the total net cash outflows under an observation of the 30 days period. The purpose of LCR is to ensure that banks maintain adequate level of high-quality liquid assets in order to be able to maintain and commit to its obligations. In the second instance, the standards promote the resilience over a longer time horizon by creating additional incentives for banks to fund their activities with more stable sources of funding on an ongoing basis. A protocol of this nature is conducted through net stable funding ratio (NSFR) analysis. This ratio is defined as the available amount of stable funding to the amount of the required stable funding. In this paper, we concentrate on net stable funding ratio (NSFR) which performs a complementary role to the LCR by promoting structural changes in liquidity risk profiles of institutions away from short-term funding mismatches and toward more stable, longer-term funding of assets and business activities. In essence, a stable funding is defined as the portion of those types and amounts of equity and liabilities financing expected to be reliable sources of funds over a one-year time horizon under conditions of extended stress. Therefore, an amount of stable funding available comprises liquidity parameters of various types of assets held, OBS contingent exposures incurred, and/or the activities pursued by the institution. This standard is required to be more than $100 \%$ to ensure that the available funding meet the required funding over the evaluated period. This ratio is defined as

Net Stable Funding Ratio (NSFR)

$$
\begin{aligned}
& =\frac{\text { Available Amount of Stable Funding (ASF) }}{\text { Required Amount of Stable Funding (RSF) }} \\
& \geq 100 \% \text {, }
\end{aligned}
$$

where stable funding includes equity and liability (Tier 1 and Tier 2 and stable deposits) reliable over the next year under conditions of extended stress and the required amount includes illiquid assets. The main objective of this standard is to provide a framework which the banks employ to repond to the market challenges by ensuring stable fundings on an ongoing basis. An additional component of the liquidity framework is a set of monitoring metric to improve crossborder supervisory consistency. In Table 4, we represent a summary of the available stable funding (ASF) and the required stable funding (RSF) components of the net stable funding ratio (NSFR) together with their multiplication factors. We define available stable funding (ASF) as the total amount of a bank's capital, preferred stock with maturity equal to one year or more than a year, liabilities with effective maturities of one year or greater, demand deposits and/or term deposits with maturities less than a year, and wholesale funding with maturities less than a year. In this ratio, extended borrowing from the central bank lending facilities outside regular open market operations is not encouraged in order not to reliy on the central bank as a source of funds. In the denominator of the NSFR, we have required stable funding for assets. We define RSF as the sum of the assets held and funded by the institution, multiplied by a specific required stable funding factor assigned to each particular asset type. This amount is measured using supervisory assumptions on the broad characteristics of the liquidity risk profiles of an institution's assets off-balance sheet exposures and other selected activities. In essence, RSF is calculated as the sum of the value of the assets held and funded by the institution, multiplied by a specific required stable funding factor assigned to each particular asset type, added to the amount of OBS activity, and multiplied by its associated RSF factor. In Table 5, we enumerate the RSF for the bank over the next one year in a stress scenario.

The overall analysis of the bank liquidity position is conducted through ratio analysis on the bank's balance sheet composition. In this case, the INSFR measures a bank's ability to access funding for a 1-year period of acute market stress. In this paper, as in Basel III, we are interested in the INSFR that was defined as the sum of interbank assets and securities issued by public entities as a percentage of interbank liabilities. The INSFR formula is given by

$$
\frac{1}{\text { NSFR }}=\frac{\text { Required Stable Funding (RSF) }}{\text { Available Stable Funding (ASF) }}
$$

This ratio of the NSFR standard is designed to

"promote a longer-term funding of the assets and
activities of banking organizations by establishing
a minimum acceptable amount of stable funding
based on the liquidity of an institution's assets and
activities over a one-year horizon."

The NSFR is a longer-term structural ratio to address liquidity mismatches and provide incentives for banks to use stable sources to fund their activities. The liquidity standard also outlines a set of standard liquidity monitoring metrics to improve cross-order supervisory consistency. These are a common set of monitoring metrics to assist supervisors in identifying and analyzing liquidity risk trends at the bank and system-wide level in order to better anticipate risks from systemic disruptions.

The overall objectivity of the BCBS for establishing the two mentioned regimes, that is, the principles for sound liquidity risk management and regulations and also the two standards, is to ensure that banks maintain high-quality liquidity levels. These levels of bank liquidity determine the quality of investments opportunities it can entertain in the financial markets, and if arbitrageurs (investors) face financial constraints, it limits the investment capacity which in turn determines the market liquidity (for more information, see e.g., [6]). In most of the cases, the economic set up of the global trading market is faced with general challenges of liquidity demand and supply. Private banks virtually serve as trading agents, and in some instances, they do demand liquidity with well-articulated investment opportunities but with no clear future investment. The public 
supply of liquidity affects the private creation of liquidity by banks, and the effects interact with firms demand for liquidity to influence investment and capital accumulation. We would say liquidity constrain contributed greatly to the lack of capital. The formation of capital market imperfections constrains investment during an emerging market financial crisis, and it makes exporters with foreign ownership to increase capital significantly. This is because many banks with foreign ownership may be able to overcome liquidity constraints by accessing overseas credit through their parent companies. In order to strengthen the liquidity management in the banks, our paper devised a stochastic optimal control problem for a continuous-time INSFR model. In essence, the control objective is to meet bank INSFR targets by making optimal choices for the two control variables, that is, the liquidity provisioning rate and asset allocation. This enables us to achieve an analytic solution to the case of quadratic cost functions (see Theorem 3 for more details).

1.1. Literature Review on BASEL III and Net Stable Funding Ratio (NSFR). Reference [7] suggests that the proposed Basel III liquidity standards constitute a cornerstone of the international regulatory reaction to the ongoing crisis. In this subsection, we survey the existing literature seeking to address liquidity problems experienced during the recent financial crisis (see, e.g., [8]). The review centres around Basel III and liquidity are introduced in $[9,10]$.

According to [11], guidance for supervisors has been augmented substantially. The guidance emphasizes the importance of supervisors assessing the adequacy of a bank's liquidity risk management framework and its level of liquidity and suggests steps that supervisors should take if these are deemed inadequate. This guidance focuses on liquidity risk management at medium and large complex banks, but the sound principles have broad applicability to all types of banks. The implementation of the sound principles by both banks and supervisors should be tailored to the size, nature of business, and complexity of a bank's activities (see [11] for more details). A bank and its supervisors also should consider the bank's role in the financial sectors of the jurisdictions in which it operates and the bank's systemic importance in those financial sectors (see, e.g., [12]). The BCBS fully expects banks and national supervisors to implement the revised principles promptly and thoroughly, and the BCBS will actively review progress in implementation. During the most severe episode of the crisis, the market lost confidence in the solvency and liquidity of many banking institutions. The weaknesses in the banking sector were rapidly transmitted to the rest of the financial system and the real economy, resulting in a massive contraction of liquidity and credit availability. Ultimately, the public sector had to step in with unprecedented injections of liquidity, capital support, and guarantees, exposing taxpayers to large losses. In response to this, during February 2008, the BCBS published [11]. The difficulties outlined in that paper highlighted that many banks had failed to take account of a number of basic principles of liquidity risk management when liquidity was plentiful. Many of the most exposed banks did not have an adequate framework that satisfactorily accounted for the liquidity risks posed by individual products and business lines, and, therefore, incentives at the business level were misaligned with the overall risk tolerance of the bank. Many banks had not considered the amount of liquidity they might need to satisfy contingent obligations, either contractual or noncontractual, as they viewed funding of these obligations to be highly unlikely.

According to [13], also, in response to the market failures revealed by the crisis, the BCBS has introduced a number of fundamental reforms to the international regulatory framework. The reforms strengthen bank level or microprudential, regulation, which will help to raise the resilience of individual banking institutions to periods of stress. Moreover, banks are mandated to comply with two ratios, that is, the LCR and the NSFR, to be effectively implemented in mitigating sovereign debt crises (see, e.g., [14, 15]). The LCR is intended to promote resilience to potential liquidity disruptions over a thirty day horizon. It will help to ensure that global banks have sufficient unencumbered, high-quality liquid assets to offset the net cash outflows it could encounter under an acute short-term stress scenario. The specified scenario is built upon circumstances experienced in the global financial crisis that began in 2007 and entails both institution-specific and systemic shocks (see, e.g., [12]). On the other hand, The NSFR aims to limit overreliance on the short-term wholesale funding during times of buoyant market liquidity and encourage better assessment of liquidity risk across all on- and off-balance sheet items.

The minimum tangible common equity requirements will increase from $2 \%$ to $4.5 \%$; in addition, banks will be asked to hold a capital conservation buffer of $2.5 \%$ to withstand future periods of stress. The new liquidity standards will be focused on two indicators: the LCR that imposes tighter controls on short-term liquidity flows and the NSFR that aims at reducing the maturity mismatch between assets and liabilities. Unfortunately, raising capital and liquidity standards may have a cost. Banks may respond to regulatory tightening by passing on additional funding costs to their retail business, by raising lending rates in order to keep the return on equity in line with market valuations, and/or by reducing the supply of credit so as to lower the share of risky assets in their balance sheets (see, e.g., [16]). Reduced credit availability and higher financing costs could affect household and firm spending. While the regulator has taken this concern into account, planning a long transition period (until 2018), the new rules could cause subdued GDP growth in the short to medium term. How large is the effect that the new rules are likely to have on GDP in Italy? Not very, according to the estimates presented in this paper. For each percentage point increase in the capital requirement, implemented over an eight-year horizon, the level of GDP relative to the baseline path would decline at trough by $0.00-0.33 \%$, depending on the estimation method (0.03-0.39\% including nonspread effects); the median decline at trough would be $0.12 \%(0.23 \%$ including nonspread effects). The trough occurs shortly after the end of the transition period; thereafter, output slowly recovers, and by the end of 2022, it is above the baseline value. 
Based on these estimates, the reduction of the annual growth rate of output in the transition period would be in a range of $0.00-0.04$ percentage points $(0.00-0.05$ percentage points including nonspread effects). The fall in output is driven for the most part by the slowdown in capital accumulation, which suffers from higher borrowing costs (and credit supply restrictions). Compliance with the new liquidity standards also yields small costs. The additional slowdown in annual GDP growth is estimated to be at most 0.02 percentage points (see, e.g., [16]). These results are broadly similar to those shown in [17], derived for the main G20 economies. If banks felt forced by competitors or financial markets to speed up the transition to the new capital standards, the fall in output could be steeper and quicker. Assuming that the transition is completed by the beginning of 2013, GDP would reach a trough in the second half of 2014; for each percentage point increase in capital requirements, GDP would slow down by $0.02-0.14$ percentage points in each year of the 2011-2013 period (see, e.g., [16]). It would subsequently rebound, partly compensating the previous fall. Long-run costs of achieving a 1-percentage point increase in the target capital ratio are also small (slightly less than $0.2 \%$ of steady state GDP); those needed to comply with the new liquidity requirements are of similar size. Econometric estimates are typically subjected to high uncertainty; those presented in this paper are of no exception. The main finding of this paper is nonetheless shared by several other studies. The economic costs of stronger capital and liquidity requirements are not huge and become negligible if compared with the potential benefits that can be reaped from reducing the frequency of systemic crises and the amplitude of boom-bust cycles. [18] evaluates that if the capital ratio increases by 1-percentage point relative to the historical average, the expected net benefits in terms of GDP level would be in a range of $0.20-$ $2.32 \%,(0.25-3.33 \%$ if liquidity requirements are also met) depending on whether financial crises are assumed to have a temporary or a permanent effect on the output. Even taking the most cautious estimate, the gains undoubtedly outweigh the costs to be paid to achieve a sounder banking system (see, e.g., [16]).

According to [19], the liquidity framework includes a module to assess risks arising from maturity transformation and rollover risks. A liquidity buffer covers small refinancing needs because of its limited size. In the management of risk, a bank can combine liquidity buffers and transparency to hedge small and large refinancing needs. A bank that can "prove" its solvency will be able to attract external refinancing.

The purpose of the nonstandard monetary policy tool suggested by Basel III is to ensure that banks build up sufficient liquidity buffers on their own to meet cash-flow obligations. At the same time, the banking system as a whole accumulates a stock of liquid reserves to safeguard financial stability. Reference [20] suggest that Basel III allows central banks to be in charge of overseeing systemic risk which places them in a position to focus on system-wide risks. Also, Basel III allows for central bank reserves which serve as means, whereby commercial banks manage their liquidity risk (see, e.g., [20]). It also assists supervisors to inform the central banks of their judgement.
1.2. Main Questions and Article Outline. In this subsection, we pose the main questions and provide an outline of the paper.

1.2.1. Main Questions. In this paper on bank net stable funding ratio, we answer the following questions.

Question 1 (banking model). Can we model banks' required stable funding (RSF) and available stable funding (ASF) as well as inverse net stable funding ratio (INSFR) in a stochastic framework where constraints are considered? (compare with Section 3).

Question 2 (bank liquidity in a numerical quantitative framework). Can we explain and provide numerical examples of the dynamics of bank inverse net stable funding ratio? (refer to Section 3.3).

Question 3 (optimal bank control problem). Can we determine the optimal control problem for a continuous-time inverse net stable funding ratio? (refer to Section 4).

1.2.2. Article Outline. This paper is organized in the following way. The current chapter introduce the paper and present a brief background of the Basel III and net stable funding ratio. In Section 2, we present simple liquidity data in order to provide insights into the relationship between liquidity and financial crises. Furthermore, Section 3 serves as a general description of the inverse net stable funding ratio modeling which is useful to the wider application for solving the optimal control problem which follows in the subsequent section. In this section, we consolidated our results by providing the dynamic model for inverse net stable funding ratio, and it gives a pictorial trend for the bank liquidity developments. Section 4 states the optimal bank inverse net stable funding ratio. This model is used to formulate the optimal stochastic INSFR control problem in Section 4 (see Question 3 and Problem 1). This involves the two main results in the paper, namely, Theorems 3 and 4 . The latter theorem is significant in that it introduces the idea of a reference process to bank INSFR dynamics (compare with Question 3). Finally in Section 5, we establish the conclusion for the paper and the possible research future directions.

\section{Liquidity in Crisis: Empirical Evidence}

In this subsection, we present simple liquidity data in order to provide insights into the relationship between liquidity and financial crises. More precisely, we discuss bank (see Section 2.1 for more details) and bond (see Section 2.2) level liquidity data. In both cases, we conclude that low liquidity coincided with periods of financial crises.

2.1. Bank Level Liquidity Data. In this subsection, we consider quarterly Call Report data on required stable funding, semirequired stable funding, illiquid assets, and illiquid guarantees from selected U.S. commercial banks during the period from Q3: 2005 to Q4: 2008. We collected data on 9067 
TABLE 1: Bank level liquidity (in billions).

\begin{tabular}{lcccc}
\hline Quarters & Required stable funding & Semirequired stable funding & Illiquid assets & Illiquid guarantees \\
\hline Q3: 2005 & 80 & 220 & 100 & 200 \\
Q4: 2005 & 30 & 200 & 280 & 220 \\
Q1: 2006 & 70 & 220 & 380 & 300 \\
Q2: 2006 & 150 & 210 & 410 & 490 \\
Q3: 2006 & 110 & 200 & 490 & 530 \\
Q4: 2006 & 180 & 230 & 500 & 620 \\
Q1: 2007 & 190 & 220 & 600 & 710 \\
Q2: 2007 & 200 & 230 & 710 & 900 \\
Q3: 2007 & 310 & 215 & 800 & 980 \\
Q4: 2007 & 270 & 230 & 820 & 1,010 \\
Q1: 2008 & 250 & 210 & 830 & 1,015 \\
Q2: 2008 & 240 & 220 & 810 & 780 \\
Q3: 2008 & 260 & 230 & 250 & 990 \\
Q4: 2008 & 310 & 250 &
\end{tabular}

distinct banks yielding 453579 bank-quarter observations over the aforementioned period.

In Table 1, we note that required stable funding decreased during the financial crisis after a steady increase before this period. As liquidity creation procedures (like bailouts) become effective in Q3: 2008 and Q4: 2008, the volume of required stable funding increased. By comparison, the semirequired stable funding fluctuated throughout the period. On the other hand, the illiquid assets increased until Q3: 2008 and then decreased as bailouts came into effect. During the financial crisis, illiquid guarantee dynamics had a negative correlation with that of required stable funding.

2.2. Bond Level Liquidity Data. In this subsection, we explore whether the effect of illiquidity is stronger during times of financial crisis. We present the results for the crisis period and compare them with those for the period with normal bond market conditions. Firstly, we provide evidence from the descriptive statistics of the key variables for the two subperiods, and then draw our main conclusions based on this. The analysis of the averages of the variables in these subperiods allows us to gain some important insights into the causes of the variation (see [21]). In this regard, Table 2 presents the mean and standard deviations for bond characteristics (amount issued, coupon, maturity, and age), trading activity variables (traded volume, number of trades, and time interval between trades), and liquidity measures (Amihud, price dispersion, Roll, and zero-return measure). The data set consists of more than 23000 U.S. corporate bonds traded over the period from Q3: 2005 to Q4: 2008.

Table 2 clearly supports the view that all liquidity measures indicated lower liquidity levels during the financial crisis. As an example, we consider the average price dispersion measure and find that its value is higher during the crisis compared to the noncrisis period. With regard to the trading activity variables, we find that the average daily volume and the trade interval at the bondlevel stay approximately constant. However, the number of trades increases during the financial crisis. These results are consistent with the level of market-wide trading activity, where we found that, during the GFC, trading takes place in fewer bonds, with an increased number of smaller size trades.

\section{An Inverse Net Stable Funding Ratio Model}

In this section, we describe aspects of INSFR modeling that are important for solving the optimal control problem outlined in Section 4. We show that concepts related to INSFRs such as volatility in available stable funding and bank investment returns may be modeled as stochastic processes. In order to construct our NSFR model, we take into account the results obtained in [22] in a discrete time framework (see, also, [23]). Here, INSFRs are closely linked to available stable funding. This liquidity design caused asymmetric and loss of information, opaqueness, and intricacy which had devastating effects on financial markets.

3.1. Description of the Inverse Net Stable Funding Ratio Model. Before the GFC, banks were prosperous with high liquidity provisioning rates, low interest rates, and soaring available stable funding. This was followed by the collapse of the housing market, exploding default rates, and the effects thereafter. We make the following assumption to set the space and time indexes that we consider in our INSFR model.

Assumption 1 (filtered probability space and time indexes). Throughout, we assume that we are working with a filtered probability space $(\Omega, \mathscr{F}, \mathbf{P})$ with filtration $\left\{\mathscr{F}_{t}\right\}_{t \geq 0}$ on a time index set $T=\left[t_{0}, t_{1}\right]$.

Furthermore, we are able to produce a system of stochastic differential equations that provide information about required stable funding value at time $t$ with $x^{1}: \Omega \times T \rightarrow$ $\mathbb{R}^{+}$denoted by $x_{t}^{1}$ and appraised available stable funding at time $t$ with $x^{2}: \Omega \times T \rightarrow \mathbb{R}^{+}$denoted by $x_{t}^{2}$ and their relationship. The dynamics of required stable funding, $x_{t}^{1}$, 
TABLE 2: Bond level liquidity.

\begin{tabular}{lcccc}
\hline & & Mean & \multicolumn{2}{c}{ Standard deviation } \\
& Noncrisis & Crisis & Noncrisis & 0.03 \\
Amount issued (bln) & 0.45 & 0.54 & 0.05 & 0.06 \\
Coupon (\%) & 6.24 & 6.23 & 0.20 & 0.05 \\
Maturity (yr) & 7.75 & 8.31 & 0.12 & 0.18 \\
Age (yr) & 4.36 & 4.76 & 0.22 & 0.14 \\
Volume (mln) & 1.44 & 1.53 & 0.24 & 0.32 \\
Trades & 4.06 & 5.33 & 0.49 & 7.42 \\
Trade interval (dy) & 3.38 & 3.37 & 1.83 & 0.48 \\
Amihud (bp per mln) & 53.21 & 89.20 & 10.57 & 35.75 \\
Price dispersion (bp) & 39.75 & 70.02 & 21.84 \\
Roll (bp) & 142.82 & 209.77 & 0.01 \\
Zero return (\%) & 0.02 & 0.03 & 52.34 \\
\hline
\end{tabular}

is stochastic in nature because, in part, it depends on the stochastic rates of return on bank assets (see [24] for more details) as well as cash in- and outflows. Also, the dynamics of available stable fundings, $x_{t}^{2}$, is stochastic because its value has a reliance on the rate of change of available stable funding as well as liquidity provisioning and risk that have randomness associated with them. Furthermore, for $x: \Omega \times T \rightarrow \mathbb{R}^{2}$, we use the notation $x_{t}$ to denote

$$
x_{t}=\left[\begin{array}{l}
x_{t}^{1} \\
x_{t}^{2}
\end{array}\right]
$$

and represent the INSFR with $l: \Omega \times T \rightarrow \mathbb{R}^{+}$by

$$
l_{t}=\frac{x_{t}^{1}}{x_{t}^{2}} .
$$

It is important for banks that $l_{t}$ in (4) has to be sufficiently high to ensure high INSFRs. Obviously, low values of $l_{t}$ indicate that the bank has low liquidity and is at high risk of causing a credit crunch. Bank liquidity has a heavy reliance on liquidity provisioning rates. Roughly speaking, this rate should be reduced for high INSFRs and increased beyond the normal rate when bank INSFRs are too low. In the sequel, the stochastic process $u^{1}: \Omega \times T \rightarrow \mathbb{R}^{+}$is the normal liquidity provisioning rate per available stable funding unit whose value at time $t$ is denoted by $u_{t}^{1}$. In this case, $u_{t}^{1} d t$ turns out to be the liquidity provisioning rate per unit of the available stable funding over the time period $(t, t+d t)$. A notion related to this is the bailout rate per unit of the available stable funding for higher or lower INSFRs, $u^{2}: \Omega \times T \rightarrow \mathbb{R}^{+}$, that will in closed loop be made dependent on the INSFR. Here, the equity amount is reliant on required stable funding deficit over available stable fundings. We denote the sum of $u^{1}$ and $u^{2}$ by the liquidity provisioning rate $u^{3}: \Omega \times T \rightarrow \mathbb{R}^{+}$, that is,

$$
u_{t}^{3}=u_{t}^{1}+u_{t}^{2}, \quad \forall t
$$

Before and during the GFC, the INSFR decreased significantly as a consequence of rising available stable fundings. During this period, extensive cash outflows took place. Banks bargained on continued growth in the financial markets (see, e.g., [22]). The following assumption is made in order to model the INSFR in a stochastic framework.

Assumption 2 (Liquidity Provisioning Rate). The liquidity provisioning rate, $u^{3}$, is predictable with respect to $\left\{\mathscr{F}_{t}\right\}_{t \geq 0}$ and provides us with a means of controlling bank INSFR dynamics (see (5) for more details).

The closed loop system will be defined such that Assumption 2 is met, as we will see in the sequel. The dynamics of the change per unit of the available stable funding, $e: \Omega \times T \rightarrow \mathbb{R}$, are given by

$$
d e_{t}=r_{t}^{e} d t+\sigma_{t}^{e} d W_{t}^{e}, \quad e\left(t_{0}\right)=e_{0},
$$

where $e_{t}$ is the change per unit of the available stable funding, $r^{e}: T \rightarrow \mathbb{R}$ is the rate of change per unit of the available stable funding, the scalar $\sigma^{e}: T \rightarrow \mathbb{R}$ is the volatility in the change per available stable funding unit, and $W^{e}: \Omega \times T \rightarrow$ $\mathbb{R}$ is standard Brownian motion. Furthermore, we consider

$$
d h_{t}=r_{t}^{h} d t+\sigma_{t}^{h} d W_{t}^{h}, \quad h\left(t_{0}\right)=h_{0},
$$

where the stochastic processes $h: \Omega \times T \rightarrow \mathbb{R}^{+}$are the asset return per unit of required stable funding, $r^{h} \rightarrow \mathbb{R}^{+}$is the rate of required stable funding return per required stable funding unit, the scalar $\sigma^{h}: T \rightarrow \mathbb{R}$ is the volatility in the rate of asset returns, and $W^{h}: \Omega \times T \rightarrow \mathbb{R}$ is standard Brownian motion. Before the GFC, risky asset returns were much higher than those of riskless assets, making the former a more attractive but much riskier investment. It is inefficient for banks to invest all in risky or riskless securities with asset allocation being important. In this regard, it is necessary to make the following assumption to distinguish between risky and riskless assets for future computations.

Assumption 3 (bank required stable funding). Suppose from the outset that bank required stable funding can be classified into $n+1$ asset classes. One of these assets is risk free (like treasury securities) while the assets $1,2, \ldots, n$ are risky. 
The risky assets evolve continuously in time and are modelled using a $n$-dimensional Brownian motion. In this multidimensional context, the asset returns in the kth asset class per unit of the kth class are denoted by $y_{t}^{k}, k \in \mathbb{N}_{n}=$ $\{0,1,2, \ldots, n\}$, where $y: \Omega \times T \rightarrow \mathbb{R}^{n+1}$. Thus, the asset return per required stable funding unit may be represented by

$$
y=\left(\mathrm{T}(t), y_{t}^{1}, \ldots, y_{t}^{n}\right),
$$

where $\mathrm{T}(t) t$ represents the return on riskless assets, and $y_{t}^{1}, \ldots, y_{t}^{n}$ represents the risky return. Furthermore, we can model $y$ as

$$
d y_{t}=r_{t}^{y} d t+\Sigma_{t}^{y} d W_{t}^{y}, \quad y\left(t_{0}\right)=y_{0},
$$

where $r^{y}: T \rightarrow \mathbb{R}^{n+1}$ denotes the rate of asset returns, $\Sigma_{t}^{y} \in$ $\mathbb{R}^{(n+1) \times n}$ is a matrix of asset returns, and $W^{y}: \Omega \times T \rightarrow \mathbb{R}^{n}$ is a standard Brownian. Notice that there are only $n$ scalar Brownian motions due to one of the assets being riskless.

We assume that the investment strategy $\pi: T \rightarrow \mathbb{R}^{n+1}$ is outside the simplex

$$
\begin{aligned}
S=\left\{\pi \in \mathbb{R}^{n+1}:\right. & \pi=\left(\pi^{0}, \ldots, \pi^{n}\right)^{T}, \\
& \pi^{0}+\cdots+\pi^{n}=1, \\
& \left.\pi^{0} \geq 0, \ldots, \pi^{n} \geq 0\right\} .
\end{aligned}
$$

In this case, short selling is possible. The required stable funding returns are then $h: \Omega \times R \rightarrow \mathbb{R}^{+}$, where the dynamics of $h$ can be written as

$$
d h_{t}=\pi_{t}^{T} d y_{t}=\pi_{t}^{T} r_{t}^{y} d t+\pi_{t}^{T} \Sigma_{t}^{y} d W_{t}^{y} .
$$

This notation can be simplified as follows. We denote that

$$
r^{\mathrm{T}}(t)=r^{y^{0}}(t), \quad r^{\mathrm{T}}: T \longrightarrow \mathbb{R}^{+},
$$

the rate of return on riskless assets,

$$
\begin{aligned}
& r_{t}^{y}=\left(r^{\mathrm{T}}(t),{\widetilde{r_{t}^{y}}}^{T}+r^{\mathrm{T}}(t) 1_{n}\right)^{T}, \quad \widetilde{r}^{y}: T \longrightarrow \mathbb{R}^{n}, \\
& \pi_{t}=\left(\pi_{t}^{0}, \tilde{\pi}_{t}^{T}\right)^{T}=\left(\pi_{t}^{0}, \pi_{t}^{1}, \ldots, \pi_{t}^{k}\right)^{T}, \quad \tilde{\pi}: T \longrightarrow \mathbb{R}^{k}, \\
& \Sigma_{t}^{y}=\left(\begin{array}{ccc}
0 & \cdots & 0 \\
& \widetilde{\Sigma}_{t}^{y}
\end{array}\right), \quad \widetilde{\Sigma}_{t}^{y} \in \mathbb{R}^{n \times n}, \\
& \widetilde{C}_{t}=\widetilde{\Sigma}_{t}^{y}{\widetilde{\Sigma_{t}^{y}}}^{T} \text {. Then, we have that } \\
& \pi_{t}^{T} r_{t}^{y}=\pi_{t}^{0} r^{\mathrm{T}}(t)+\tilde{\pi}_{t}^{j T} \widetilde{r}_{t}^{y}+\widetilde{\pi}_{t}^{j T} r^{\mathrm{T}}(t) 1_{n} \\
& =r^{\mathrm{T}}(t)+\widetilde{\pi}_{t}^{T} \widetilde{r}_{t}^{y}, \\
& \pi_{t}^{T} \Sigma_{t}^{y} d W_{t}^{y}=\widetilde{\pi}_{t}^{T} \widetilde{\Sigma}_{t}^{y} d W_{t}^{y}, \\
& d h_{t}=\left[r^{\mathrm{T}}(t)+\widetilde{\pi}_{t}^{T} \widetilde{r}_{t}^{y}\right] d t+\widetilde{\pi}_{t}^{T} \widetilde{\Sigma}_{t}^{y} d W_{t}^{y}, \quad h\left(t_{0}\right)=h_{0} .
\end{aligned}
$$

Next, we take $i: \Omega \times T \rightarrow \mathbb{R}^{+}$as the available stable funding increase before change per unit of available stable funding, $r^{i}: T \rightarrow \mathbb{R}^{+}$is the rate of increase of available stable fundings before change, per available stable funding unit, the scalar $\sigma^{i} \in \mathbb{R}$ is the volatility in the increase of available stable funding before change and $W^{i}: \Omega \times T \rightarrow \mathbb{R}$ represents standard Brownian motion. Then, we set

$$
d i_{t}=r_{t}^{i} d t+\sigma^{i} d W_{t}^{i}, \quad i\left(t_{0}\right)=i_{0} .
$$

The stochastic process $i_{t}$ in (13) may typically originate from available stable funding volatility that may result from changes in market activity, supply, and inflation.

We can choose from two approaches when modeling our INSFR in a stochastic setting. The first is a realistic model that incorporates all the aspects of the INSFR like available stable funding, required stable fundings, and risks linked with liquidity. Alternatively, we can develop a simple model which acts as a proxy for something more realistic that emphasizes features that are specific to our particular study. In our situation, we choose the latter option, with the model for required stable fundings, $x^{1}$, and available stable funding, $x^{2}$, and their relationship being derived as

$$
\begin{aligned}
d x_{t}^{1}= & x_{t}^{1} d h_{t}+x_{t}^{2} u_{t}^{3} d t-x_{t}^{2} d e_{t} \\
= & {\left[r^{\mathrm{T}}(t) x_{t}^{1}+x_{t}^{1} \widetilde{\pi}_{t}^{T} \widetilde{r}_{t}^{y}+x_{t}^{2} u_{t}^{1}+x_{t}^{2} u_{t}^{2}-x_{t}^{2} r_{t}^{e}\right] d t } \\
& +\left[x_{t}^{1} \widetilde{\pi}_{t}^{T} \widetilde{\Sigma}_{t}^{y} d W_{t}^{y}-x_{t}^{2} \sigma^{e} d W_{t}^{e}\right], \\
d x_{t}^{2}= & x_{t}^{2} d i_{t}-x_{t}^{2} d e_{t} \\
= & x_{t}^{2}\left[r_{t}^{i} d t+\sigma^{i} d W_{t}^{i}\right]-x_{t}^{2}\left[r_{t}^{e} d t+\sigma^{e} d W_{t}^{e}\right] \\
= & x_{t}^{2}\left[r_{t}^{i}-r_{t}^{e}\right] d t+x_{t}^{2}\left[\sigma^{i} d W_{t}^{i}-\sigma^{e} d W_{t}^{e}\right] .
\end{aligned}
$$

The SDEs (14) may be rewritten into matrix-vector form in the following way.

Definition 1 (stochastic system for the INSFR model). Define the stochastic system for the INSFR model as

$$
d x_{t}=A_{t} x_{t} d t+N\left(x_{t}\right) u_{t} d t+a_{t} d t+S\left(x_{t}, u_{t}\right) d W_{t},
$$

with the various terms in this stochastic differential equation being

$$
\begin{aligned}
& u_{t}=\left[\begin{array}{l}
u_{t}^{2} \\
\widetilde{\pi}_{t}
\end{array}\right], \quad u: \Omega \times T \longrightarrow \mathbb{R}^{n+1}, \\
& A_{t}=\left[\begin{array}{cc}
r^{\mathrm{T}}(t) & -r_{t}^{e} \\
0 & r_{t}^{i}-r_{t}^{e}
\end{array}\right], \\
& N\left(x_{t}\right)=\left[\begin{array}{cc}
x_{t}^{2} & x_{t}^{1}{\widetilde{r_{t}^{y}}}^{T} \\
0 & 0
\end{array}\right], \quad a_{t}=\left[\begin{array}{c}
x_{t}^{2} u_{t}^{1} \\
0
\end{array}\right] \text {, } \\
& S\left(x_{t}, u_{t}\right)=\left[\begin{array}{ccc}
x_{t}^{1} \widetilde{\pi}_{t}^{T} \widetilde{\Sigma}_{t}^{y} & -x_{t}^{2} \sigma^{e} & 0 \\
0 & -x_{t}^{2} \sigma^{e} & x_{t}^{2} \sigma^{i}
\end{array}\right], \\
& W_{t}=\left[\begin{array}{l}
W_{t}^{y} \\
W_{t}^{e} \\
W_{t}^{i}
\end{array}\right],
\end{aligned}
$$


where $W_{t}^{y}, W_{t}^{e}$, and $W_{t}^{i}$ are mutually (stochastically) independent standard Brownian motions. It is assumed that for all $t \in T, \sigma_{t}^{e}>0, \sigma_{t}^{i}>0$, and $\widetilde{C}_{t}>0$. Often the time argument of the functions $\sigma^{e}$ and $\sigma^{i}$ are omitted.

We can rewrite (15) as follows:

$$
\begin{aligned}
& N\left(x_{t}\right) u_{t}:=\left[\begin{array}{c}
x_{t}^{2} \\
0
\end{array}\right] u_{t}^{2}+\left[\begin{array}{c}
x_{t}^{1} \widetilde{r}_{t}^{r^{T}} \\
0
\end{array}\right] \tilde{\pi}_{t} \\
& :=\left[\begin{array}{ll}
0 & 1 \\
0 & 0
\end{array}\right] x_{t} u_{t}^{3}+\sum_{m=1}^{n}\left[\begin{array}{c}
x_{t}^{1} \widetilde{r}_{t}^{y, m} \\
0
\end{array}\right] \tilde{\pi}_{t}^{m} \\
& :=B_{0} x_{t} u_{t}^{0}+\sum_{m=1}^{n}\left[\begin{array}{cc}
\widetilde{r}_{t}^{y, m} & 0 \\
0 & 0
\end{array}\right] x_{t} \tilde{\pi}_{t}^{m} \\
& :=\sum_{m=0}^{n}\left[B_{m} x_{t}\right] u_{t}^{m}, \\
& S\left(x_{t}, u_{t}\right) d W_{t}=\left[\begin{array}{cc}
{\left[\tilde{\pi}_{t}^{T} \widetilde{C}_{t} \widetilde{\pi}_{t}\right]^{1 / 2}} & 0 \\
0 & 0
\end{array}\right] x_{t} d W_{t}^{1} \\
& +\left[\begin{array}{ll}
0 & -\sigma^{e} \\
0 & -\sigma^{e}
\end{array}\right] x_{t} d W_{t}^{2}+\left[\begin{array}{cc}
0 & 0 \\
0 & \sigma^{i}
\end{array}\right] x_{t} d W_{t}^{3} \\
& =\sum_{j=1}^{3}\left[M^{j j}\left(u_{t}\right) x_{t}\right] d W_{t}^{j j},
\end{aligned}
$$

where $B$ and $M$ are only used for notational purposes to simplify the equations. From the stochastic system given by (15), it is clear that $u=\left(u^{2}, \tilde{\pi}\right)$ affects only the stochastic differential equation of $x_{t}^{1}$ but not that of $x_{t}^{2}$. In particular, for (15), we have that $\tilde{\pi}$ affects the variance of $x_{t}^{1}$ and the drift of $x_{t}^{1}$ via the term $x_{t}^{1} \widetilde{r}_{t}^{r^{T}} \tilde{\pi}_{t}$. On the other hand, $u^{2}$ affects only the drift of $x_{t}^{1}$. Then, (15) becomes

$$
\begin{aligned}
d x_{t}= & A_{t} x_{t} d t+\sum_{j=0}^{n}\left[B^{j} x_{t}\right] u_{t}^{j} d t+a_{t} d t \\
& +\sum_{j=1}^{3}\left[M^{j}\left(u_{t}\right) x_{t}\right] d W_{t}^{j j} .
\end{aligned}
$$

3.2. Description of the Simplified INSFR Model. The model can be simplified if attention is restricted to the system with the INSFR, as stated earlier, denoted in this section by $x_{t}=$ $x_{t}^{1} / x_{t}^{2}$.

Definition 2 (stochastic model for a simplified INSFR). Define the simplified INSFR system by the SDE

$$
\begin{aligned}
d x_{t}= & x_{t}\left[r^{T}(t)+r_{t}^{e}-r_{t}^{i}+\left(\sigma^{e}\right)^{2}+\left(\sigma^{i}\right)^{2}+{\widetilde{r_{t}^{y}}}^{T} \tilde{\pi}_{t}\right] d t \\
& +\left[u_{t}^{1}+u_{t}^{2}-r_{t}^{e}-\left(\sigma^{e}\right)^{2}\right] d t
\end{aligned}
$$

$$
\begin{array}{r}
+\left[\left(\sigma^{e}\right)^{2}\left(1-x_{t}\right)^{2}+\left(\sigma^{i}\right)^{2} x_{t}^{2}+x_{t}^{2} \widetilde{\pi}_{t}^{T} \widetilde{C}_{t} \widetilde{\pi}_{t}\right]^{1 / 2} d \bar{W}_{t}, \\
x\left(t_{0}\right)=x_{0} .
\end{array}
$$

The model is derived as follows. The starting point is the two-dimensional SDE for $x=\left(x^{1}, x^{2}\right)^{T}$ as in (14). Next, we determine

$$
\begin{aligned}
& d\left(x_{t}^{2}\right)^{-1}=-\left(x_{t}^{2}\right)^{-2} d x_{t}^{2}+\frac{1}{2} 2\left(x^{2}\right)_{t}^{-3} d<x^{2}, \quad x^{2}>t \\
& =\left[-\left(x^{2}\right)_{t}^{-1}\left(r_{t}^{i}-r_{t}^{e}\right)+\left(x_{t}^{2}\right)^{-1}\left(\left(\sigma^{e}\right)^{2}+\left(\sigma^{i}\right)^{2}\right)\right] d t \\
& -\left(x_{t}^{2}\right)^{-1}\left[\begin{array}{lll}
0 & -\sigma^{e} & \sigma^{i}
\end{array}\right] d W_{t}, \\
& d x_{t}=x_{t}^{1} d\left(x_{t}^{2}\right)^{-1}+\left(x_{t}^{2}\right)^{-1} d x_{t}^{1}+d<x^{1}, \quad\left(x^{2}\right)^{-1}>t \\
& =\left[r^{\mathrm{T}}(t) x_{t}-r_{t}^{e}+u_{t}^{1}+u_{t}^{2}+x_{t} \widetilde{r}_{t}^{y} \tilde{\pi}_{t}\right. \\
& \left.-x_{t}\left[r_{t}^{i}-r_{t}^{e}\right]+x_{t}\left(\left(\sigma^{e}\right)^{2}+\left(\sigma^{i}\right)^{2}\right)-\left(\sigma^{e}\right)^{2}\right] d t \\
& +\left(x_{t} \widetilde{\pi}_{t}^{T} \widetilde{\Sigma}_{t}^{y}-\sigma^{e}\left(1-x_{t}\right)-\sigma^{i} x_{t}\right) d W_{t} \\
& =x_{t}\left[r^{\mathrm{T}}(t)+r_{t}^{e}-r_{t}^{i}+\left(\sigma^{e}\right)^{2}+\left(\sigma^{i}\right)^{2}+{\widetilde{r_{t}^{y}}}^{T} \tilde{\pi}_{t}\right] d t \\
& +\left[u_{t}^{1}+u_{t}^{2}-r_{t}^{e}-\left(\sigma^{e}\right)^{2}\right] d t \\
& +\left[\left(\sigma^{e}\right)^{2}\left(1-x_{t}\right)^{2}+\left(\sigma^{i}\right)^{2}\left(x_{t}\right)^{2}\right. \\
& \left.+\left(x_{t}\right)^{2} \tilde{\pi}_{t}^{T} \widetilde{C}_{t} \tilde{\pi}_{t}+\left(\sigma^{i}\right)^{2}\left(x_{t}\right)^{2}\right]^{1 / 2} d \bar{W}_{t},
\end{aligned}
$$

for a stochastic process $\bar{W}: \Omega \times T \rightarrow \mathbb{R}$ which is a standard Brownian motion. Note that in the drift of the SDE (19), the term

$$
-r_{t}^{e}+x_{t} r_{t}^{e}=-r_{t}^{e}\left(x_{t}-1\right)
$$

appears because it models the effect of depreciation of both required stable fundings and available stable funding. Similarly the term $-\left(\sigma^{e}\right)^{2}+x_{t}\left(\sigma^{e}\right)^{2}=\left(\sigma^{e}\right)^{2}\left(x_{t}-1\right)$ appears.

The predictions made by our previously constructed model are consistent with the empirical evidence in contributions such as $[23,25]$. For instance, in much the same way as we do, [23] describes how available stable fundings affect INSFRs. On the other hand, to the best of our knowledge, the modeling related to collateral and INSFR reference processes (see Section 4 for a comprehensive discussion) has not been tested in the literature before. One of the main contributions of the paper is the way the INSFR model is constructed by using stochastic techniques. We believe that this is an addition to the preexisting literature because it captures some of the uncertainty associated with INSFR variables. In this regard, we provide a theoretical-quantitative modeling 


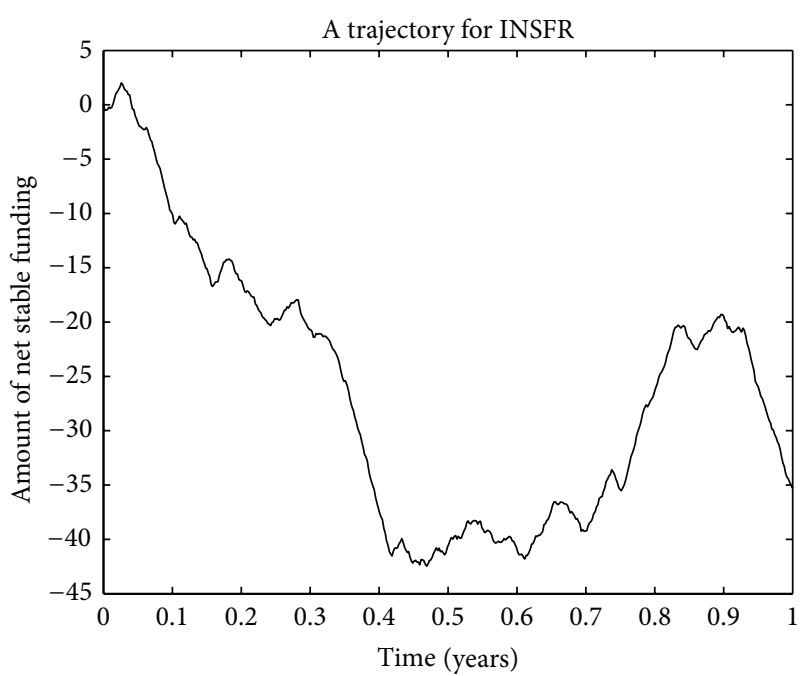

FIGURE 1: Trajectory of the INSFR of stable fundings.

TABLE 3: Choices of inverse net stable funding ratio parameters.

\begin{tabular}{lc}
\hline Parameter & Value \\
\hline$C$ & 500 \\
$r^{i}$ & 0.01 \\
$\tilde{r}^{y}$ & 0.06 \\
$u^{2}$ & 0.03 \\
$r^{C}$ & 0.05 \\
$\sigma^{e}$ & 1.6 \\
$\widetilde{\pi}$ & 0.4 \\
$\widetilde{C}$ & 150 \\
$r^{e}$ & 0.04 \\
$\sigma^{i}$ & 1.8 \\
$u^{1}$ & 0.01 \\
$\bar{W}$ & 0.03 \\
\hline
\end{tabular}

framework for establishing bank INSFR reference processes and the making of decisions about liquidity provisioning rates and asset allocation.

3.3. Liquidity Simulation. In this subsection, we provide a simulation of the INSFR dynamics given in (19).

3.3.1. INSFR Simulation. In this subsubsection, we provide parameters and values for a numerical simulation. The parameters and their corresponding values for the simulation are shown below.

3.3.2. INSFR Dynamics: Numerical Example. In Figure 1, we provide the INSFR dynamics in the form of a trajectory derived from (19).

3.3.3. Properties of the INSFR Trajectory: Numerical Example. Figure 1 shows the simulated trajectory for the INSFR for stable funding for the bank. Here, different values of banking parameters are collected in Table 3. The number of jumps of the trajectory was limited to 500, with the initial values for I fixed at 100. The new Basel III formulated quantitative framework in the form of standards which play some complementary role to the existing principles for sound liquidity risk management and regulations. In this framework, we intend to regulate liquidity risk in the banks adopting quantitative method. This typically involves setting a liquidity ratio as a minimum requirement, which, however, complemented by broader systems and control related to management of liquidity risk.

As we know, banks manage their liquidity by offsetting liabilities via assets. It is actually the diversification of the bank's assets and liabilities that expose them to liquidity shocks. Here, we use ratio analysis (in the form of the INSFR) to manage liquidity risk relating various components in the bank's balance sheets. Figure 1 depicts that the bank had some difficulties to secure some stable funding between $0.1 \leq t \leq$ 0.3 and also $0.7 \leq t \leq 0.9$. The ratio for INSFR dictates that the amount of net stable funding should be $\leq 1$. Hence, we have some higher liquidity ratio between $0.4 \leq t \leq 0.7$, and this is because the growth of the required stable funding by the bank was higher than that of the available stable funding. At this stage, the bank might have diversified ways of attracting resources through issuing new bonds and selling securities.

There was an even sharper increase subsequent to $t=0.7$ which comes as somewhat of a surprise. In order to mitigate the aforementioned increase in liquidity risk, banks can use several facilities such as repurchase agreements to secure more funding. In order for banks to improve liquidity they may use debt securities that allow savings from nonfinancial private sectors, a good network of branches, and other competitive strategies. It is important for banks that $l_{t}$ in (4) has to be sufficiently high to ensure high INSFRs. Obviously, low values of $l_{t}$ indicate that the bank has low liquidity and is at high risk of causing a credit crunch.

Bank liquidity has a heavy reliance on liquidity provisioning rates. Roughly speaking, this rate should be reduced for high INSFRs and increased beyond the normal rate when bank INSFRs are too low.

\section{Optimal Bank Inverse Net Stable Funding Ratios}

In order for a bank to determine an optimal bank bailout rate (seen as an adjustment to the normal provisioning rate) and asset allocation strategy, it is imperative that a welldefined objective function with appropriate constraints is considered. The choice has to be carefully made in order to avoid ambiguous solutions to our stochastic control problem.

4.1. The Optimal Bank INSFR Problem. In our contribution, we choose to determine a control law $g\left(t, x_{t}\right)$ that minimizes the cost function $J: \mathscr{G}_{A} \rightarrow \mathbb{R}^{+}$, where $\mathscr{G}_{A}$ is the class of admissible control laws

$$
\mathscr{G}_{A}=\left\{g: T \times\left.\mathscr{X} \longrightarrow \mathscr{U}\right|_{g}\right. \text { Borel measurable function }
$$

and there exists a unique solution

to the closed-loop system\}, 


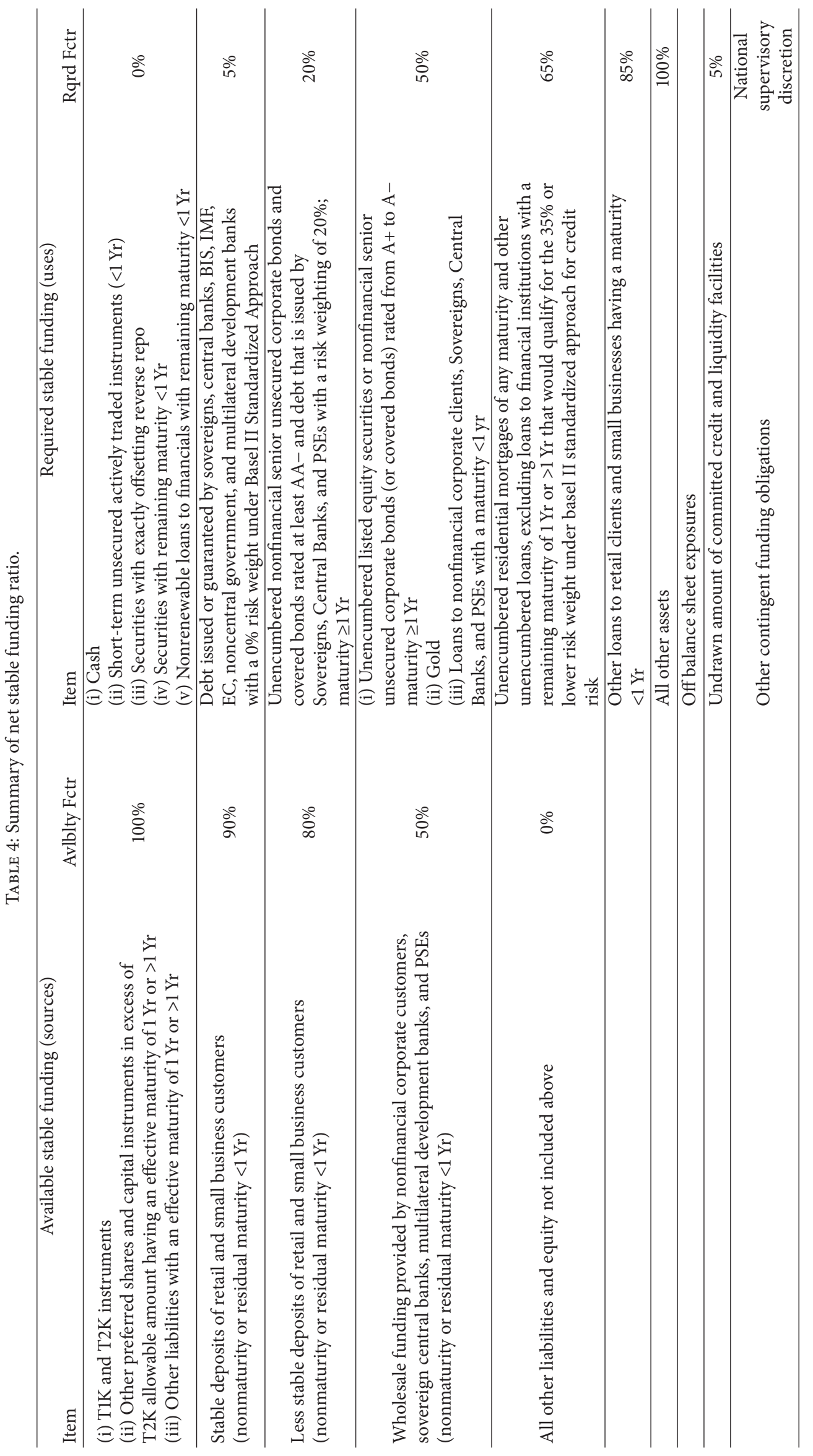


TABLE 5: Detailed composition of asset categories and associated RSF factors.

RSF factor Components of RSF category

(i) Cash immediately available to meet obligations, not currently encumbered as collateral and not held for planned use (as contingent collateral, salary payments, or for other reasons)

(ii) Unencumbered short-term unsecured instruments and transactions with outstanding maturities of less than one year ${ }^{1}$

$0 \%$

(iii) Unencumbered securities with stated remaining maturities of less than one year with no embedded options that would increase the expected maturity to more than one year

(iv) Unencumbered securities held where the institution has an offsetting reverse repurchase transaction when the security on each transaction has the same unique identifier (e.g., ISIN number or CUSIP)

(v) Unencumbered loans to financial entities with effective remaining maturities of less than one year that are not renewable and for which the lender has an irrevocable right to call

Unencumbered marketable securities with residual maturities of one year or greater representing claims on or claims guaranteed by sovereigns, central banks, BIS, IMF, EC, noncentral government PSEs or multilateral development banks that are assigned a 0\% risk-weight under the Basel II Standardized Approach, provided that active repo or sale-markets exist for these securities

(i) Unencumbered corporate bonds or covered bonds rated AA- or higher with residual maturities of one year or greater satisfying all of the conditions for L2As in the LCR, outlined in Paragraph 42(b)

(ii) Unencumbered marketable securities with residual maturities of one year or greater representing claims on or claims guaranteed by sovereigns, central banks, noncentral government PSEs that are assigned a 20\% risk weight under the Basel II Standardized Approach, provided that they meet all of the conditions for Level 2 assets in the LCR, outlined in Paragraph $42(a)$

(i) Unencumbered gold

(ii) Unencumbered equity securities, not issued by financial institutions or their affiliates listed on a recognized exchange and included in a large cap market index

(iii) Unencumbered corporate bonds and covered bonds that satisfy all of the following conditions:

(a) central bank eligibility for intraday liquidity needs and overnight liquidity shortages in relevant jurisdictions ${ }^{2}$

(b) not issued by financial institutions or their affiliates (except in the case of covered bonds)

(c) not issued by the respective firm itself or its affiliates

(d) Low credit risk: assets have a credit assessment by a recognized ECAI of $\mathrm{A}+$ to $\mathrm{A}-$, or do not have a credit assessment by a recognized ECAI and are internally rated as having a PD corresponding to a credit assessment of $\mathrm{A}+$ to $\mathrm{A}-$

(e) traded in large, deep, and active markets characterized by a low level of concentration

(iv) Unencumbered loans to nonfinancial corporate clients, sovereigns, central banks, and PSEs having a remaining maturity of less than one year

(i) Unencumbered residential mortgages of any maturity that would qualify for the $35 \%$ or lower risk weight under Basel II Standardized Approach for credit risk

(ii) Other unencumbered loans, excluding loans to financial institutions, with a remaining maturity of one year or greater, that would qualify for the 35\% or lower risk weight under Basel II Standardized Approach for credit risk

$85 \%$ Unencumbered loans to retail customers (i.e., natural persons) and small business customers (as defined in the LCR) having a remaining maturity of less than one year (other than those that qualify for the $65 \%$ RSF above)

$100 \%$ All other assets not included in the above categories

Such instruments include but are not limited to: short-term government and corporate bills; notes and obligations; commercial paper; negotiable certificates of deposits; reserves with central banks and sale transactions of such funds (e.g., fed funds sold); bankers acceptances; money market mutual funds.

${ }^{2}$ See Footnote 8 for further discussion of central bank eligibility.

with the closed-loop system for $g \in \mathscr{G}_{A}$ being given by

$$
\begin{aligned}
d x_{t}= & A_{t} x_{t} d t+\sum_{j=0}^{n} B^{j} x_{t} g^{j}\left(t, x_{t}\right) d t+a_{t} d t \\
& +\sum_{j=1}^{3} M^{j j}\left(g\left(t, x_{t}\right)\right) x_{t} d W_{t}^{j j}, \quad x\left(t_{0}\right)=x_{0} .
\end{aligned}
$$

Furthermore, the cost function, $J: \mathscr{G}_{A} \rightarrow \mathbb{R}^{+}$, of the INSFR problem is given by

$$
\begin{gathered}
J(g)=\mathbf{E}\left[\int_{t_{0}}^{t_{1}} \exp \left(-r^{f}\left(l-t_{0}\right)\right) b\left(l, x_{l}, g\left(l, x_{l}\right)\right) d l\right. \\
\left.\quad+\exp \left(-r^{f}\left(t_{1}-t_{0}\right)\right) b^{1}\left(x\left(t_{1}\right)\right)\right],
\end{gathered}
$$


where $g \in \mathscr{G}_{A}, T=\left[t_{0}, t_{1}\right]$, and $b^{1}: \mathscr{X} \rightarrow \mathbb{R}^{+}$is a Borel measurable function. Furthermore, $b: T \times \mathscr{X} \times \mathscr{U} \rightarrow \mathbb{R}^{+}$is formulated as

$$
b(t, x, u)=b^{2}\left(u^{2}\right)+b^{3}\left(\frac{x^{1}}{x^{2}}\right),
$$

for $b^{2}: \mathscr{U}_{2} \rightarrow \mathbb{R}^{+}$and $b^{3}: \mathbb{R}^{+} \rightarrow \mathbb{R}^{+}$. Also, $r^{f} \in \mathbb{R}$ is called the forecasting rate of available stable funding. The functions $b^{1}, b^{2}$ and $b^{3}$, are selected below where various choices are considered. In order to clarify the stochastic problem, the following assumption should be made.

Assumption 4 (admissible class of control laws). Assume that $\mathscr{G}_{A} \neq \emptyset$.

We are now in a position to state the stochastic optimal control problem for a continuous-time INSFR model that we solve. The said problem may be formulated as follows.

Problem 1 (optimal bank Insfr problem). Consider the stochastic control system in (23) for the INSFR problem with the admissible class of control laws, $\mathscr{G}_{A}$, given by (22) and the cost function, $J: \mathscr{G}_{A} \rightarrow \mathbb{R}^{+}$, given by (24). Solve

$$
\inf _{g \in \mathscr{G}_{A}} J(g)
$$

which amounts to determining the value $J^{*}$, given by

$$
J^{*}=\inf _{g \in \mathscr{G}_{A}} J(g)
$$

and the optimal control law $g^{*}$, if it exists,

$$
g^{*}=\arg \min _{g \in \mathscr{G}_{A}} J(g) \in \mathscr{G}_{A} \text {. }
$$

4.2. Optimal Bank INSFRs in the Simplified Case. Consider the simplified system in (19) for the INSFR problem with the admissible class of control laws, $\mathscr{G}_{A}$, given by (22) but with $\mathscr{X}=\mathbb{R}$. In this section, we have to solve

$$
\begin{gathered}
\inf _{g \in \mathscr{G}_{A}} J(g) \\
J^{*}=\inf _{g \in \mathscr{G}_{A}} J(g) \\
J(g)=\mathbf{E}\left[\int_{t_{0}}^{t_{1}} \exp \left(-r^{f}\left(l-t_{0}\right)\right)\left[b^{2}\left(u_{t}^{2}\right)+b^{3}\left(x_{t}\right)\right] \mathrm{d} t\right. \\
\left.+\exp \left(-r^{f}\left(t_{1}-t_{0}\right)\right) b^{1}\left(x\left(t_{1}\right)\right)\right]
\end{gathered}
$$

where $b^{1}: \mathbb{R} \rightarrow \mathbb{R}^{+}, b^{2}: \mathbb{R} \rightarrow \mathbb{R}^{+}$, and $b^{3}: \mathbb{R}^{+} \rightarrow \mathbb{R}^{+}$ are all Borel measurable functions. For the simplified case, the optimal cost function in (29) should be determined with the simplified cost function, $J(g)$, given by (30). In this case, assumptions have to be made in order to find a solution for the optimal cost function, $J^{*}$. Next, we state and prove an important result.
Theorem 3 (optimal bank INSFRS in the simplified case). Suppose that $g^{2 *}$ and $g^{3 *}$ are the components of the optimal control law, $g^{*}$, that deal with the optimal bailout rate, $u^{2 *}$, and optimal asset allocation, $\pi^{k *}$, respectively. Consider the nonlinear optimal stochastic control problem for the simplified INSFR system in (19) formulated in Problem 1. Suppose that the following assumptions hold.

Assumption 3.1. The cost function is assumed to satisfy

$$
\begin{gathered}
b^{2}\left(u^{2}\right) \in C^{2}(\mathbb{R}), \\
\lim _{u^{2} \rightarrow-\infty} D_{u^{2}} b^{2}\left(u^{2}\right)=-\infty, \\
\lim _{u^{2} \rightarrow+\infty} D_{u^{2}} b^{2}\left(u^{2}\right)=+\infty, \\
D_{u^{2} u^{2}} b^{2}\left(u^{2}\right)>0, \quad \forall u^{2} \in \mathbb{R},
\end{gathered}
$$

with the differential operator, $D$, which is applied in this case to function $b^{2}$.

Assumption 3.2. There exists a function $v: T \times \mathbb{R} \rightarrow \mathbb{R}$, $v \in C^{1,2}(T \times \mathscr{X})$, which is a solution of the PDE given by

$$
\begin{aligned}
0= & D_{t} v(t, x)+\frac{1}{2}\left[\left(\sigma^{e}\right)^{2}(1-x)^{2}+\left(\sigma^{i}\right)^{2}\left(x_{t}\right)^{2}\right] D_{x x} v(t, x) \\
& +x\left(r^{\mathrm{T}}(t)+r_{t}^{e}-r_{t}^{i}+\left(\sigma^{e}\right)^{2}+\left(\sigma^{i}\right)^{2}\right) D_{x} v(t, x) \\
& +\left[u_{t}^{1}-r_{t}^{e}-\left(\sigma^{e}\right)^{2}\right] D_{x} v(t, x) \\
& +u_{t}^{2^{*}} D_{x} v(t, x)+\exp \left(-r^{f}\left(t-t_{0}\right)\right) b^{2}\left(u_{t}^{2^{*}}\right) \\
& +\exp \left(-r^{f}\left(t-t_{0}\right)\right) b^{3}(x)-\frac{\left[D_{x} v(t, x)\right]^{2}}{2 D_{x x} v(t, x)} \widetilde{r}_{t}^{\frac{T}{}} \widetilde{C}_{t}^{-1} \widetilde{r}_{t}^{y} \\
& v\left(t_{1}, x\right)=\exp \left(-r^{f}\left(t_{1}-t_{0}\right)\right) b^{1}(x),
\end{aligned}
$$

where $u^{2 *}$ is the unique solution of the equation

$$
0=D_{x} v(t, x)+\exp \left(-r^{f}\left(t-t_{0}\right)\right) D_{u^{2}} b^{2}\left(u_{t}^{2}\right)
$$

Then, the optimal control law is

$$
g^{2 *}(t, x)=u^{2^{*}}, \quad g^{2^{*}}: T \times \mathscr{X} \rightarrow \mathbb{R}^{+},
$$

with $u^{2 *} \in \mathscr{U}_{2}$ the unique solution of (34)

$$
\begin{gathered}
\tilde{\pi}^{*}=-\frac{D_{x} v(t, x)}{x D_{x x} v(t, x)} \widetilde{C}_{t}^{-1} \widetilde{r}_{t}^{y}, \\
g^{3, k *}(t, x)=\min \left\{1, \max \left\{0, \tilde{\pi}^{k *}\right\}\right\}, \quad g^{3, k *}: T \times \mathscr{X} \rightarrow \mathbb{R} .
\end{gathered}
$$


Furthermore, the value of the problem is

$$
J^{*}=J\left(g^{*}\right)=\mathbf{E}\left[v\left(t, x_{0}\right)\right] .
$$

Proof. It will be proven that the minimization in the dynamic programming equation can be achieved and that there exists a solution to the dynamic programming equation.

Step 1. Recall from optimal stochastic control theory (see, e.g., [26]) that the dynamic programming equation (DPE) for the optimal control problem for $w: T \times \mathbb{R} \rightarrow \mathbb{R}, w \in C^{1,2}(T \times \mathscr{X})$, is given by

$$
\begin{aligned}
0=D_{t} w(t, x) & \\
+\inf _{u^{2} \in \mathbb{R}, \tilde{\pi} \in[0,1]}\left[\frac { 1 } { 2 } \left[\left(\sigma^{e}\right)^{2}(1-x)^{2}+\left(\sigma^{i}\right)^{2}(x)^{2}\right.\right. & \\
& \left.+(x)^{2} \widetilde{\pi}^{T} \widetilde{C}_{t} \tilde{\pi}\right] D_{x x} w(t, x) \\
+ & {\left[\left(r^{\mathrm{T}}(t)+r_{t}^{e}-r_{t}^{i}+\left(\sigma^{e}\right)^{2}+\left(\sigma^{i}\right)^{2}\right.\right.} \\
& \left.\left.+\widetilde{r}_{t}^{y^{T}} \tilde{\pi}\right) x\right] D_{x} w(t, x) \\
+ & {\left[u_{t}^{1}+u^{2}-r_{t}^{e}-\left(\sigma^{e}\right)^{2}\right] D_{x} w(t, x) } \\
+ & \left.\exp \left(-r^{f}\left(t-t_{0}\right)\right)\left[b^{2}\left(u^{2}\right)+b^{3}(x)\right]\right] \\
w\left(t_{1}, x\right)= & \exp \left(-r^{f}\left(t_{1}-t_{0}\right)\right) b^{1}(x) .
\end{aligned}
$$

Note that this DPE separates additively into terms
(a) depending on $u^{2}$,
(b) depending on $\tilde{\pi}$,
(c) not depending on either of these variables.

The minimization is therefore decomposed into two.

Step 2. The minimizations are calculated as follows with the function $v$ :

$$
\begin{gathered}
\inf _{u^{2} \in \mathbb{R}} H_{2}\left(t, x, u^{2}\right), \\
H_{2}(t, x, u)=u^{2} D_{x} v(t, x) \\
+\exp \left(-r^{f}\left(t-t_{0}\right)\right) b^{2}\left(u^{2}\right), \\
D_{u^{2} H_{2}(t, x, u)=} D_{x} v(t, x) \\
+\exp \left(-r^{f}\left(t-t_{0}\right)\right) D_{u^{2}} b^{2}\left(u^{2}\right)=0 .
\end{gathered}
$$

Because of Assumption 3.1. in the hypothesis of the theorem, (39) for all $(t, x) \in T \times \mathscr{X}$ has a unique solution $u^{2^{*}} \in \mathcal{U}=\mathbb{R}$ and

$$
\begin{aligned}
\inf _{u^{2} \in \mathbb{R}} H_{2}\left(t, x, u^{2}\right)= & H_{2}\left(t, x, u^{2^{*}}\right) \\
= & u^{2^{*}} D_{x} v(t, x) \\
& +\exp \left(-r^{f}\left(t-t_{0}\right)\right) b^{2}\left(u^{2^{*}}\right) .
\end{aligned}
$$

Define the function $g^{2}(t, x)^{*}=u^{2^{*}}, g^{2^{*}}: T \times \mathscr{X} \rightarrow$ $\mathbb{R}$. It follows from Assumption 3.1. in the hypothesis of the theorem that $g^{2 *}$ is a Borel measurable function. Consider the minimization problem

$$
\begin{aligned}
& \inf _{\tilde{\pi} \in \mathbb{R}^{k}} H_{3}(t, x, \tilde{\pi}), \\
& H_{3}(t, x, \tilde{\pi})= \frac{1}{2}\left[\tilde{\pi}_{t}^{T} \widetilde{C}_{t} \widetilde{\pi}_{t}\right](x)^{2} D_{x x} v(t, x) \\
&+\widetilde{r}_{t}^{T} \tilde{\pi} x D_{x} v(t, x) \\
&= \frac{1}{2}\left(\widetilde{\pi}_{t}+\left(\frac{x\left[D_{x} v(t, x)\right]}{(x)^{2} D_{x x} v(t, x)}\right) \widetilde{C}_{t}^{-1} \widetilde{r}_{t}^{y}\right)^{T} \\
& \times \widetilde{C}_{t}(x)^{2} D_{x x} v(t, x) \\
& \times\left(\widetilde{\pi}_{t}+\left(\frac{x\left[D_{x} v(t, x)\right]}{(x)^{2} D_{x x} v(t, x)}\right) \widetilde{C}_{t}^{-1} \widetilde{r}_{t}^{y}\right) \\
&-\frac{1}{2}\left(\frac{\left[x D_{x} v(t, x)\right]^{2}}{(x)^{2} D_{x x} v(t, x)}\right) \widetilde{r}_{t}^{T} \widetilde{C}_{t}^{-1} \widetilde{r}_{t}^{y}, \\
& \widetilde{C}_{t}(x)^{2} D_{x x} v(t, x)>0, \quad \forall x \in \mathbb{R} \backslash\{0\} .
\end{aligned}
$$

Hence, we have that

$$
\begin{gathered}
\tilde{\pi}^{*}=-\frac{D_{x} v(t, x)}{x D_{x x} v(t, x)} \widetilde{C}_{t}^{-1} \widetilde{r}_{t}^{y}, \\
g^{3, k *}(t, x)=\left\{\begin{array}{l}
\tilde{\pi}^{k *}, \quad \text { if } \sum_{i=1}^{k} \widetilde{\pi}^{i *} \in[0,1], \\
\frac{\tilde{\pi}^{k *}}{\sum_{j=1}^{k} \tilde{\pi}^{j *}}, \quad \text { if } \sum_{i=1}^{k} \widetilde{\pi}^{i *}>1,
\end{array} \quad \forall k \in \mathbb{Z}^{n},\right. \\
H_{3}\left(t, x, \tilde{\pi}^{*}\right)=-\frac{\left[D_{x} v(t, x)\right]^{2}}{2 D_{x x} v(t, x)}\left(\widetilde{r}_{t}^{y}\right)^{T} \widetilde{C}_{t}^{-1} \widetilde{r}_{t}^{y} .
\end{gathered}
$$

If for a $k \in \mathbb{Z}^{n}, \tilde{\pi}^{k *} \notin[0,1]$, then the DPE (32) has to be modified with the difference of the terms obtained with and 
without the constraint. This is not indicated in the current paper.

Step 3. We can rewrite (32) by using the infima obtained in Step 2 and the DPE for $v$. The resulting equation is

$$
\begin{aligned}
& 0=D_{t} v(t, x) \\
& +\inf _{u^{2} \in \mathbb{R}, \tilde{\pi} \in[0,1]}\left\{\begin{array}{l}
\frac{1}{2}\left[\left(\sigma^{e}\right)^{2}(1-x)^{2}+\left(\sigma^{i}\right)^{2}(x)^{2}\right. \\
\left.+(x)^{2}\left(\tilde{\pi}^{T} \widetilde{C}_{t} \tilde{\pi}\right)\right] D_{x x} v(t, x)
\end{array}\right. \\
& +\left[r^{T}(t)+r_{t}^{e}-r_{t}^{i}+\left(\sigma^{e}\right)^{2}\right. \\
& \left.+\left(\sigma^{i}\right)^{2}+\widetilde{r}_{t}^{T} \tilde{\pi}\right] x \\
& +\left[u_{t}^{1}+u^{2}-r_{t}^{e}-\left(\sigma^{e}\right)^{2}\right] D_{x} v(t, x) \\
& \left.+\exp \left(-r^{f}\left(t-t_{0}\right)\right)\left[b^{2}\left(u^{2}\right)+b^{3}(x)\right]\right\}, \\
& v \\
& v\left(t_{1}, x\right)=\exp \left(-r^{f}\left(t_{1}-t_{0}\right)\right) b^{1}(x) .
\end{aligned}
$$

Thus $v$, whose existence is assumed by Assumption 2 in the hypothesis of the theorem, is a solution of the dynamic programming equation. It follows then from the standard optimal stochastic control as in [26] that $g^{2 *}$ and $g^{3, k *}$ are the optimal control laws and that the value is given by $J^{*}=$ $J\left(g^{*}\right)=\mathbf{E}\left[v\left(t_{0}, x_{0}\right)\right]$.

In Theorem 3, we assume that the cost function in (30) satisfies constraints represented by (31). Secondly, there exists a functions (33) that is a solution to (32). Then, the optimal control law is given by (35) and (36), where $u^{2 *}$ is a solution to (34). Finally, the optimal cost function is given by (37). It is of interest to choose particular cost functions for which an analytic solution can be obtained for the value function and for the control laws. The following theorem provides the optimal control laws for a particular choice of cost functions.

Theorem 4 (optimal bank INSFRs with quadratic cost functions). Consider the nonlinear optimal stochastic control problem for the simplified INSFR system in (19) formulated in Problem 1. Consider the cost function

$$
\begin{aligned}
J(g)=\mathbf{E}\left[\int_{t_{0}}^{t_{1}} \exp \left(-r^{f}\left(l-t_{0}\right)\right)\right. \\
\quad \times\left[\frac{1}{2} c^{2}\left(\left(u^{2}\right)^{2}(l)\right)+\frac{1}{2} c^{3}\left(x_{t}-l^{r}\right)^{2}\right] d l \\
\left.+\frac{1}{2} c^{1}\left(x\left(t_{1}\right)-l^{r}\right)^{2} \exp \left(-r^{f}\left(t_{1}-t_{0}\right)\right)\right] .
\end{aligned}
$$

It is assumed that the cost functions satisfy

$$
\begin{array}{ll}
b^{1}(x)=\frac{1}{2} c^{1}\left(x-l^{r}\right)^{2}, & c^{1} \in(0, \infty) \\
b^{2}\left(u^{2}\right)=\frac{1}{2} c^{2}\left(u^{2}\right)^{2}, & c^{2} \in(0, \infty) \\
b^{3}(x)=\frac{1}{2} c^{3}\left(x-l^{r}\right)^{2}, & c^{3} \in(0, \infty),
\end{array}
$$

$l^{r} \in \mathbb{R}$, called the reference value of the INSFR.

Define the first-order ODE

$$
\begin{aligned}
-\dot{q}_{t}= & -\frac{\left(q_{t}\right)^{2}}{c^{2}}+c^{3}+q_{t} 2\left(r^{\mathrm{T}}(t)+r_{t}^{e}-r_{t}^{i}+\left(\sigma^{e}\right)^{2}+\left(\sigma^{i}\right)^{2}\right) \\
& +q_{t}\left[-r^{f}-\widetilde{r}_{t}^{y} \widetilde{C}_{t}^{-1} \widetilde{r}_{t}^{y}+\left(\sigma^{e}\right)^{2}+\left(\sigma^{i}\right)^{2}\right], \quad q_{t_{1}}=c^{1} \\
-\dot{x}_{t}^{r}= & -\frac{c^{3}\left(x_{t}^{r}-l^{r}\right)}{q_{t}} \\
& -x_{t}^{r}\left[r^{\mathrm{T}}(t)+r_{t}^{e}-r_{t}^{i}+\left(\sigma^{e}\right)^{2}+\left(\sigma^{i}\right)^{2}\right] \\
& -\left[u_{t}^{1}-r_{t}^{e}-\left(\sigma^{e}\right)^{2}\right]-\left(x_{t}^{r}-1\right)\left(\left(\sigma^{e}\right)^{2}+\left(\sigma^{i}\right)^{2}\right) \\
& -\left(\sigma^{i}\right)^{2}, \quad x^{r}\left(t_{1}\right)=l^{r}, \\
-\dot{l}_{t}= & -r^{f} l_{t}+c^{3}\left(x_{t}^{r}-l^{r}\right)^{2}-q_{t}\left(\sigma^{e}\right)^{2}\left(x_{t}^{r}-1\right)^{2} \\
& -q_{t}\left(\sigma^{i}\right)^{2}\left(x_{t}^{r}\right)^{2}, \quad l\left(t_{1}\right)=0
\end{aligned}
$$

The function $x^{r}: T \rightarrow \mathbb{R}$ will be called the INSFR reference (process) function. Then, we have the following.

(a) There exist solutions to the ordinary differential equations (47), (48), and (49). Moreover, for all $t \in T$, $q_{t}>0$.

(b) The optimal control laws are

$$
\begin{gathered}
u_{t}^{2^{*}}=-\frac{\left(x-x_{t}^{r}\right) q_{t}}{c^{2}}, \\
g^{2^{*}}(t, x)=u^{2^{*}}, \quad g^{2^{*}}: T \times \mathscr{X} \longrightarrow \mathbb{R}^{+}, \\
\tilde{\pi}_{t}^{*}=-\frac{\left(x-x_{t}^{r}\right)}{x} \widetilde{C}_{t}^{-1} \widetilde{r}_{t}^{y}, \quad g^{3^{*}}: T \times \mathscr{X} \longrightarrow \mathbb{R}^{k}, \\
g^{3, k *}(t, x)=\left\{\begin{array}{cc}
\tilde{\pi}^{k *}, & \text { if } \tilde{\pi}^{k *} \in[0,1], \\
\min \left\{1, \max \left\{0, \tilde{\pi}_{t}^{k *}\right\}\right\}, & \text { otherwise, }
\end{array}\right.
\end{gathered}
$$

$\forall k \in \mathbb{Z}^{n}$

(c) The value function and the value of the problem are

$$
\begin{gathered}
v(t, x)=\exp \left(-r^{f}\left(t_{1}-t_{0}\right)\right)\left[\frac{1}{2}\left(x-x_{t}^{r}\right)^{2} q_{t}+\frac{1}{2} l_{t}\right], \\
J^{*}=J\left(g^{*}\right)=\mathbf{E}\left[v\left(t_{0}, x_{0}\right)\right] .
\end{gathered}
$$


Proof. (a) The ordinary differential equation in (47) is of Riccati type. It follows from, for example, [27, Theorem 37, page 364] that a unique solution to this equation exists.

The second statement requires a longer argument. Rewrite the Riccati differential equation in (47) in the form,

$$
\begin{gathered}
-\dot{q}_{t}=-b\left(q_{t}\right)^{2}+c+2 a_{t} q_{t}, \quad q_{t_{1}}=c^{1}, \\
b=\frac{1}{c^{2}}, \quad c=c^{3} \in(0, \infty), \quad a: T \longrightarrow \mathbb{R} .
\end{gathered}
$$

Transform the equation according to

$$
\begin{gathered}
q_{t_{1}}^{1}=q\left(t_{1}-t\right), \quad a_{t}^{1}=a\left(t_{1}-t\right), \quad q^{1}:\left[0, t_{1}-t_{0}\right] \rightarrow \mathbb{R}, \\
\dot{q}_{t}^{1}=-\dot{q}\left(t_{1}-t\right)=-b\left(q_{t}^{1}\right)^{2}+c+2 a_{t}^{1} q_{t}^{1}, \quad q_{t_{0}}^{1}=c^{1}, \\
0=\dot{q}_{t}^{1}+b\left(q_{t}^{1}\right)^{2}-c-2 a_{t}^{1} q_{t}, \quad q_{0}^{1}=c^{1} .
\end{gathered}
$$

Consider the second Riccati differential equation

$$
-\dot{q}_{t}^{2}=-\bar{b}\left(q_{t}^{2}\right)^{2}+\bar{c}, \quad q_{t_{1}}^{2}=c^{1} ; \quad \bar{b}, \bar{c} \in(0, \infty) .
$$

The latter Riccati differential equation is time invariant. The associated first-order linear system with system matrices $(0, \sqrt{(b)}, \sqrt{(c)})$ is both controllable and observable. It then follows from a result for this Riccati differential equation that $q_{t}^{2}>0$ for all $t \in T=\left[0, t_{1}-t_{0}\right]$.

Next a theorem is used from [28, Lemma 5.1] in the comparison of the solutions of the two Riccati differential equations. The lemma states that for all $t \in\left[t_{1}-t_{0}\right], q_{t}^{1} \geq$ $q_{t}^{2}>0$ if,

$$
b \in(0, \infty), \quad\left(\begin{array}{cc}
-\bar{c} & 0 \\
0 & \bar{b}
\end{array}\right) \geq\left(\begin{array}{cc}
-c & -a_{t}^{1} \\
-a_{t}^{1} & b
\end{array}\right), \quad \forall t \in\left[0, t_{1}-t_{0}\right]
$$

The matrix inequality is met if and only if

$$
\begin{gathered}
b \in(0, \infty), \quad(\bar{b}-b) \geq 0, \quad(c-\bar{c}) \geq 0, \\
\left(a_{t}\right)^{2} \leq(c-\bar{c})(\bar{b}-b)=\left(c^{3}-\bar{c}^{3}\right)\left(\frac{1}{\bar{c}^{2}}-\frac{1}{c^{2}}\right) .
\end{gathered}
$$

By assumption, all functions in $a$ and, hence, those of $a_{t}^{1}=$ $a\left(t_{1}-t\right)$ are bounded on the bounded interval $\left[0, t_{1}-t_{0}\right]$. Hence, there exists a constant $c^{4} \in(0, \infty)$ such that $\left(a_{t}^{1}\right)^{2}<c^{4}$. Then, one can determine real numbers $\bar{b}, \bar{c} \in(0, \infty)$ such that

$$
\begin{gathered}
c-\bar{c}=c^{3}-\bar{c}^{3} \geq 0, \quad \bar{b}-b=\frac{1}{\bar{c}^{2}}-\frac{1}{c^{2}} \geq 0, \\
\left(a_{t}\right)^{2} \leq c^{4} \leq(c-\bar{c})(\bar{b}-b)=\left(c^{3}-\bar{c}^{3}\right)\left(\frac{1}{\bar{c}^{2}}-\frac{1}{c^{2}}\right),
\end{gathered}
$$

for example, by choosing $\bar{c}^{2}, \bar{c}^{3} \in(0, \infty)$ both very small. Thus the inequalities are satisfied and for all $t \in\left[0, t_{1}-t_{0}\right], q\left(t_{1}-\right.$ $t)=q_{t}^{1} \geq q_{t}^{2}>0$.

The ordinary differential equation (48) is linear (see, e.g., [29]). Hence, it follows for such differential equations that a unique solution exists.

$(b, c)$ The cost function $b^{2}$ satisfies the conditions of Theorem 3. It will be proven that the function (52) is a solution of the partial differential equation, (32) and, (33) of Theorem 3.

Note first that

$$
\begin{gathered}
v(t, x)=\exp \left(-r^{f}\left(t-t_{0}\right)\right)\left[\frac{1}{2}\left(x-x_{t}^{r}\right)^{2} q_{t}+\frac{1}{2} l_{t}\right], \\
D_{t} v(t, x)=-r^{f} v(t, x)+\exp \left(-r^{f}\left(t-t_{0}\right)\right) \\
\times\left[-\left(x-x_{t}^{r}\right) \dot{x}^{r}{ }_{t} q_{t}+\frac{1}{2}\left(x-x_{t}^{r}\right)^{2} \dot{q}_{t}+\frac{1}{2} \dot{l}_{t}\right], \\
D_{x} v(t, x)=\exp \left(-r^{f}\left(t-t_{0}\right)\right)\left(x-x_{t}^{r}\right) q_{t}, \\
D_{x x} v(t, x)=\exp \left(-r^{f}\left(t-t_{0}\right)\right) q_{t} .
\end{gathered}
$$

The optimal control laws are calculated according to the formulas of the previous theorem.

So

$$
\begin{gathered}
0=D_{x} v(t, x)+\exp \left(-r^{f}\left(t-t_{0}\right)\right) D_{u^{2}} b^{2}\left(u^{2}\right) \\
=\exp \left(-r^{f}\left(t-t_{0}\right)\right)\left[\left(x-x_{t}^{r}\right) q_{t}+c^{2} u^{2}\right], \\
u^{2^{*}}=-\frac{\left(x-x_{t}^{r}\right) q_{t}}{c^{2}}, \\
\tilde{\pi}^{*}=-\frac{\left(x-x_{t}^{r}\right) q_{t}}{x q_{t}} \widetilde{C}_{t}^{-1} \widetilde{r}_{t}^{y} .
\end{gathered}
$$

From the partial differential equation in (32) and the terminal condition in (33) it follows that

$$
\begin{aligned}
q_{t_{1}}=c^{1}, & x^{r}\left(t_{1}\right)=l^{r}, \quad l\left(t_{1}\right)=0, \\
v\left(t_{1}, x\right)= & \exp \left(-r^{f}\left(t_{1}-t_{0}\right)\right) \\
& \times\left[\frac{1}{2}\left(x-x^{r}\left(t_{1}\right)\right)^{2} q_{t_{1}}+\frac{1}{2} l\left(t_{1}\right)\right] \\
= & \exp \left(-r^{f}\left(t_{1}-t_{0}\right)\right) \frac{1}{2} c^{1}\left(x-l^{r}\right)^{2} \\
= & \exp \left(-r^{f}\left(t_{1}-t_{0}\right)\right) b^{1}(x),
\end{aligned}
$$




$$
\begin{aligned}
& \exp \left(+r^{f}\left(t-t_{0}\right)\right) \\
& \times\left[D_{t} v(t, x)+\frac{1}{2}\left[\left(\sigma^{e}\right)^{2}(1-x)^{2}\right.\right. \\
& \left.+\left(\sigma^{i}\right)^{2}(x)^{2}\right] D_{x x} v(t, x) \\
& +x\left[r^{\mathrm{T}}(t)+r_{t}^{e}-r_{t}^{i}+\left(\sigma^{e}\right)^{2}+\left(\sigma^{i}\right)^{2}\right] D_{x} v(t, x) \\
& +\left[u_{t}^{1}-r_{t}^{e}-\left(\sigma^{e}\right)^{2}\right] D_{x} v(t, x) \\
& +u^{2^{*}} D_{x} v(t, x)+\exp \left(-r^{f}\left(t-t_{0}\right)\right) b^{2}\left(u^{2^{*}}\right) \\
& +\exp \left(-r^{f}\left(t-t_{0}\right)\right) b^{3}(x) \\
& \left.-\frac{1}{2} \frac{\left(D_{x} v(t, x)\right)^{2}}{D_{x x} v(t, x)} \widetilde{r}_{t}^{T} \widetilde{C}_{t}^{-1} \widetilde{r}_{t}^{y}\right] \\
& =-r^{f} \frac{1}{2}\left(x-x_{t}^{r}\right)^{2} q_{t}-\frac{1}{2} r^{f} l_{t}-\left(x-x_{t}^{r}\right) q_{t} \dot{x}_{t}^{r} \\
& +\frac{1}{2}\left(x-x_{t}^{r}\right)^{2} \dot{q}_{t}+\frac{1}{2} \dot{l}_{t} \\
& +\frac{1}{2}\left[\left(\sigma^{e}\right)^{2}(1-x)^{2}+\left(\sigma^{i}\right)^{2}(x)^{2}\right] q_{t} \\
& +\left(x-x_{t}^{r}\right) q_{t}\left[x\left(r^{\mathrm{T}}(t)+r_{t}^{e}-r_{t}^{i}+\left(\sigma^{e}\right)^{2}+\left(\sigma^{i}\right)^{2}\right)\right. \\
& \left.+u_{t}^{1}-r_{t}^{e}-\left(\sigma^{e}\right)^{2}\right] \\
& -\frac{1}{2} \frac{\left(x-x_{t}^{r}\right)^{2}\left(q_{t}\right)^{2}}{c^{2}} \\
& +\frac{1}{2} c^{3}\left(x-l^{r}\right)^{2}-\frac{1}{2}\left(x-x_{t}^{r}\right)^{2} q_{t}{\widetilde{r_{t}^{y}}}^{T} \widetilde{C}_{t}^{-1} \widetilde{r}_{t}^{y} \\
& =\frac{1}{2}(x)^{2}\left[-r^{f} q_{t}+\dot{q}_{t}+\left(\sigma^{e}\right)^{2} q_{t}+\left(\sigma^{i}\right)^{2} q_{t}\right. \\
& +2 q_{t}\left[r^{\mathrm{T}}(t)+r_{t}^{e}-r_{t}^{i}+\left(\sigma^{e}\right)^{2}+\left(\sigma^{i}\right)^{2}\right] \\
& \left.-\frac{\left(q_{t}\right)^{2}}{c^{2}}+c^{3}-q_{t}{\widetilde{r_{t}^{y}}}^{T} \widetilde{C}_{t}^{-1} \widetilde{r}_{t}^{y}\right] \\
& +x\left[+r^{f} x_{t}^{r} q_{t}-q_{t} \dot{x}_{t}^{r}-x_{t}^{r} \dot{q}_{t}-\left(\sigma^{e}\right)^{2} q_{t}\right. \\
& -x_{t}^{r} q_{t}\left[r^{\mathrm{T}}(t)+r_{t}^{e}-r_{t}^{i}+\left(\sigma^{e}\right)^{2}+\left(\sigma^{i}\right)^{2}\right] \\
& +q_{t}\left[u_{t}^{1}-r_{t}^{e}-\left(\sigma^{e}\right)^{2}\right]+\frac{x_{t}^{r}\left(q_{t}\right)^{2}}{c^{2}} \\
& \left.-c^{3} l^{r}+x_{t}^{r} q_{t}{\widetilde{r_{t}^{y}}}^{T} \widetilde{C}_{t}^{-1} \widetilde{r}_{t}^{y}\right]
\end{aligned}
$$

$$
\begin{aligned}
+\frac{1}{2}(x)^{0}[ & -r^{f}\left(x_{t}^{r}\right)^{2} q_{t}+2 x_{t}^{r} q_{t} \dot{x}_{t}^{r}+\left(x_{t}^{r}\right)^{2} \dot{q}_{t}-r^{f} l_{t} \\
& +\left(\sigma^{e}\right)^{2} q_{t}-2 x_{t}^{r} q_{t}\left[u_{t}^{1}-r_{t}^{e}-\left(\sigma^{e}\right)^{2}\right] \\
& -\frac{\left(x_{t}^{r}\right)^{2}\left(q_{t}\right)^{2}}{c^{2}}+c^{3}\left(l^{r}\right)^{2} \\
& \left.-\left(x_{t}^{r}\right)^{2} \widetilde{q}_{t} \widetilde{r}_{t}^{y} \widetilde{C}_{t}^{-1} \widetilde{r}_{t}^{y}+\dot{l}_{t}\right] .
\end{aligned}
$$

It will be proven that the terms at the powers of the indeterminate $x$ are zero, thus, at $(x)^{2},(x)^{1}$, and $(x)^{0}$. The term at $(x)^{2}$ is zero due to the differential equation for $q$. The term at $(x)^{1}$ equals

$$
\begin{aligned}
& -q_{t} \dot{x}_{t}^{r}-x_{t}^{r} \dot{q}_{t}+r^{f} x_{t}^{r} q_{t}-2\left(\sigma^{e}\right)^{2} q_{t} \\
& -x_{t}^{r} q_{t}\left[r^{\mathrm{T}}(t)+r_{t}^{e}-r_{t}^{i}+\left(\sigma^{e}\right)^{2}+\left(\sigma^{i}\right)^{2}\right] \\
& +q_{t}\left[u_{t}^{1}-r_{t}^{e}-\left(\sigma^{e}\right)^{2}\right] \\
& +\frac{x_{t}^{r}\left(q_{t}\right)^{2}}{c^{2}}-c^{3} l^{r}+x_{t}^{r} q_{t}{\widetilde{r_{t}^{y}}}^{T} \widetilde{C}_{t}^{-1} \widetilde{r}_{t}^{y} \\
& =-q_{t} \dot{x}_{t}^{r} \\
& +x_{t}^{r}\left[-\frac{\left(q_{t}\right)^{2}}{c^{2}}+c^{3}\right. \\
& +2 q_{t}\left(r^{\mathrm{T}}(t)+r_{t}^{e}-r_{t}^{i}+\left(\sigma^{e}\right)^{2}+\left(\sigma^{i}\right)^{2}\right) \\
& \left.+q_{t}\left(\left(\sigma^{e}\right)^{2}+\left(\sigma^{i}\right)^{2}-r^{f}-{\widetilde{r_{t}^{y}}}^{T} \widetilde{C}_{t}^{-1} \widetilde{r}_{t}^{y}\right)\right] \\
& -x_{t}^{r} q_{t}\left[\left(r^{\mathrm{T}}(t)+r_{t}^{e}-r_{t}^{i}+\left(\sigma^{e}\right)^{2}+\left(\sigma^{i}\right)^{2}\right)\right. \\
& \left.-r^{f}-{\widetilde{r_{t}^{y}}}^{T} \widetilde{C}_{t}^{-1} \widetilde{r}_{t}^{y}\right] \\
& +q\left[-\left(\sigma^{e}\right)^{2}+\left(u_{t}^{1}-r_{t}^{e}-\left(\sigma^{e}\right)^{2}\right)\right]+\frac{x_{t}^{r}\left(q_{t}\right)^{2}}{c^{2}}-c^{3} l^{r} \\
& =q_{t}\left[-\dot{x}_{t}^{r}+\frac{c^{3}\left(x_{t}^{r}-l^{r}\right)}{q_{t}}\right] \\
& +x_{t}^{r}\left[r^{\mathrm{T}}(t)+r_{t}^{e}-r_{t}^{i}+\left(\sigma^{e}\right)^{2}+\left(\sigma^{i}\right)^{2}\right] \\
& +\left(x_{t}^{r}-1\right)\left(\left(\sigma^{e}\right)^{2}+\left(\sigma^{i}\right)^{2}\right)+\left(\sigma^{i}\right)^{2} \\
& +\left(u_{t}^{1}-r_{t}^{e}-\left(\sigma^{e}\right)^{2}\right) \\
& =0 \text {. }
\end{aligned}
$$


Similarly, the term of $(x)^{0}$ equals

$$
\begin{aligned}
\dot{l}_{t}-r^{f} l_{t} & -r^{f}\left(x_{t}^{r}\right)^{2} q_{t} \\
& +2 x_{t}^{r}\left[q_{t} \dot{x}_{t}^{r}+x_{t}^{r} \dot{q}_{t}\right]-\left(x_{t}^{r}\right)^{2} \dot{q}_{t}+\left(\sigma^{e}\right)^{2} q_{t} \\
& -2 x_{t}^{r} q_{t}\left[u_{t}^{1}-r_{t}^{e}-\left(\sigma^{e}\right)^{2}\right]+c^{3}\left(l^{r}\right)^{2}-\frac{\left(x_{t}^{r}\right)^{2}\left(q_{t}\right)^{2}}{c^{2}} \\
& -\left(x_{t}^{r}\right)^{2} q_{t}{\widetilde{r_{t}^{y}}}^{T} \widetilde{C}_{t}^{-1} \widetilde{r}_{t}^{y}
\end{aligned}
$$

$=\left(\right.$ using the term with $\left.(x)^{1}\right)$,

$$
\dot{l}_{t}-r^{f} l_{t}-r^{f}\left(x_{t}^{r}\right)^{2} q_{t}+\left(\sigma^{e}\right)^{2} q_{t}
$$$$
-2 x_{t}^{r} q_{t}\left[u_{t}^{1}-r_{t}^{e}-\left(\sigma^{e}\right)^{2}\right]+c^{3}\left(l^{r}\right)^{2}
$$$$
-\frac{\left(x_{t}^{r}\right)^{2}\left(q_{t}\right)^{2}}{c^{2}}-\left(x_{t}^{r}\right)^{2} q_{t}{\widetilde{r_{t}^{y}}}^{T} \widetilde{C}_{t}^{-1} \widetilde{r}_{t}^{y}
$$$$
+2 r^{f}\left(x_{t}^{r}\right)^{2} q_{t}-2 x_{t}^{r} q_{t}\left(\sigma^{e}\right)^{2}
$$$$
-2\left(x_{t}^{r}\right)^{2} q_{t}\left[r^{T}+r^{e}-r^{i}+\left(\sigma^{e}\right)^{2}+\left(\sigma^{i}\right)^{2}\right]
$$$$
+2 x_{t}^{r} q_{t}\left[u_{t}^{1}-r_{t}^{e}-\left(\sigma^{e}\right)^{2}\right]-c^{3} l^{r} 2 x_{t}^{r}
$$$$
+\frac{2\left(x_{t}^{r}\right)^{2}\left(q_{t}\right)^{2}}{c^{2}}+2\left(x_{t}^{r}\right)^{2} q_{t}{\widetilde{r_{t}^{y}}}^{T} \widetilde{C}_{t}^{-1} \widetilde{r}_{t}^{y}
$$$$
-\frac{\left(x_{t}^{r}\right)^{2}\left(q_{t}\right)^{2}}{c^{2}}+c^{3}\left(x_{t}^{r}\right)^{2}
$$$$
+\left(x_{t}^{r}\right)^{2} q_{t} 2\left(r^{\mathrm{T}}+r^{e}-r^{i}+\left(\sigma^{e}\right)^{2}+\left(\sigma^{i}\right)^{2}\right)
$$$$
+\left(x_{t}^{r}\right)^{2} q_{t}\left(-r^{f}+\left(\sigma^{e}\right)^{2}+\left(\sigma^{i}\right)^{2}-{\widetilde{r_{t}^{y}}}^{T} \widetilde{C}_{t}^{-1} \widetilde{r}_{t}^{y}\right)
$$$$
=\dot{l}_{t}-r^{f} l_{t}+c^{3}\left(x_{t}^{r}-l^{r}\right)^{2}-\left(\sigma^{e}\right)^{2} q_{t}\left(x_{t}^{r}-1\right)^{2}
$$$$
-\left(\sigma^{i}\right)^{2} q_{t}\left(x_{t}^{r}\right)^{2}
$$

$=0$.

It then follows from Theorem 3 that the indicated control laws are the optimal ones (see, e.g., [26]).

4.3. Comments on Optimal Bank INSFRs. The control objective is to meet bank INSFR targets by making optimal choices for the two control variables, namely, the liquidity provisioning rate and asset allocation. The objective, to meet these targets, is formulated as a cost on the INSFR, $x$, in the simplified model. The first control variable, the liquidity provisioning rate, is formulated as a cost on bank bailouts, $u^{2}$, that embeds liquidity risk. As for the mathematical form for the cost functions, we have considered several options that are discussed below. Of course, one can formulate any cost function. The question then is whether the resulting dynamic programming equation can be solved analytically.
We have obtained an analytic solution so far only for the case of quadratic cost functions (see Theorem 4 for more details).

For the cost on the bank bailout, the function in (45) is considered, where the input variable $u^{2}$ is restricted to the set $\mathbb{R}^{+}$. If $u^{2}>0$, then the banks should acquire additional required stable funding. The cost function should be such that bank bailouts are maximized; hence $u^{2}>0$ should imply that $b^{2}\left(u^{2}\right)>0$. In general, it seems best to maximize liquidity provisioning. For Theorem 4 , we have selected the cost function $b^{2}\left(u^{2}\right)=(1 / 2) c^{2}\left(u^{2}\right)^{2}$, given by (45). This penalizes both positive and negative values of $u^{2}$ in equal ways. The only reason for doing so is that then an analytic solution of the value function can be obtained.

The reference process, $l^{r}$, may take the value 0.8 , that is, the threshold for negative INSFR. The cost on meeting liquidity provisioning will be encoded in a cost on the INSFR. If the INSFR, $x>l^{r}$, is strictly larger than a set value $l^{r}$, then there should be a strictly positive cost. If, on the other hand, $x<l^{r}$, then there may be a cost though most banks will be satisfied and not impose a cost. We have selected the cost function $b^{3}(x)=(1 / 2) c^{3}\left(x-l^{r}\right)^{2}$ in Theorem 4 given by (46). This is also done to obtain an analytic solution of the value function, and that case by itself is interesting. Another cost function that we consider is

$$
b^{3}(x)=c^{3}\left[\exp \left(x-l^{r}\right)+\left(l^{r}-x\right)-1\right],
$$

which is strictly convex and asymmetric in $x$ with respect to the value $l^{r}$. For this cost function, costs with $x>l^{r}$ are penalized higher than those with $x<l^{r}$. This seems realistic. Another cost function considered is to keep $b^{3}(x)=0$ for $x<l^{r}$.

An interpretation of the control laws given by (50) follows. The bank bailout rate, $u^{2^{*}}$, is proportional to the difference between the INSFR, $x$, and the reference process for this ratio, $x^{r}$. The proportionality factor is $q_{t} / c^{2}$ which depends on the relative ratio of the cost function on $u^{2}$ and the deviation from the reference ratio, $\left(x-x^{r}\right)$. The property that the control law is symmetric in $x$ with respect to the reference process $x^{r}$ is a direct consequence of the cost function $b^{r}(x)=(1 / 2) c^{3}\left(x-x^{r}\right)^{2}$ being symmetric with respect to $\left(x-x^{r}\right)$. The optimal portfolio distribution is proportional to the relative difference between the INSFR and its reference process, $\left(x-x_{t}^{r}\right) / x$. This seems natural. The proportionality factor is $\widetilde{C}_{t}^{-1} \widetilde{r}_{t}^{y}$ which represents the relative rates of asset return multiplied with the inverse of the corresponding variances. It is surprising that the control law has this structure. Apparently, the optimal control law is not to liquidate first all required stable funding with the highest liquidity provisioning rate and then the required stable fundings with the next to highest liquidity provisioning rate, and so on. The proportion of all required stable fundings depend on the relative weighting in $\widetilde{C}_{t}^{-1} \widetilde{r}_{t}^{y}$ and not on the deviation $\left(x-x_{t}^{r}\right)$.

The novel structure of the optimal control law is the reference process for the INSFR, $x^{r}: T \rightarrow \mathbb{R}$. The differential equation for this reference function is given by (48). This differential equation is new for the area of INSFR control and 
therefore deserves a discussion. The differential equation has several terms on its right-hand side which will be discussed separately. Consider the term,

$$
u_{t}^{1}-r_{t}^{e}-\left(\sigma^{e}\right)^{2}
$$

This represents the difference between primary required stable funding change and available stable funding. Note that $u_{t}^{1}$ is the normal liquidity provisioning rate, and $r_{t}^{e}$ is the rate of required stable funding increase. Note that if $\left[u_{t}^{1}-\right.$ $\left.r_{t}^{e}-\left(\sigma^{e}\right)^{2}\right]>0$, then the reference INSFR function can be increasing in time due to this inequality so that for $t>$ $t_{1}, x_{t}<l^{r}$. The term $c^{3}\left(x_{t}^{r}-l^{r}\right) / q_{t}$ models that if the reference INSFR function is smaller than $l^{r}$, then the function has to increase with time. The quotient $c^{3} / q_{t}$ is a weighting term which accounts for the running costs and for the effect of the solution of the Riccati differential equation. The term

$$
x_{t}^{r}\left[r^{\mathrm{T}}(t)+r_{t}^{e}-r_{t}^{i}+\left(\sigma^{e}\right)^{2}+\left(\sigma^{i}\right)^{2}\right]
$$

accounts for two effects. The difference $r_{t}^{e}-r_{t}^{i}$ is the net effect of rate of asset return, $r^{e}$, and that of the change in available stable funding. The term $r^{\mathrm{T}}(t)+\left(\sigma^{e}\right)^{2}+\left(\sigma^{i}\right)^{2}$ is the effect of the increase in the available stable funding due to the riskless asset and the variance of the risky liquidity provisioning. The last term

$$
\left(x_{t}^{r}-1\right)\left(\left(\sigma^{e}\right)^{2}+\left(\sigma^{i}\right)^{2}\right)-\left(\sigma^{i}\right)^{2}
$$

accounts for the effect on required stable fundings and available stable funding. More information is obtained by streamlining the ODE for $x^{r}$. In order to rewrite the differential equation for $x^{r}$, it is necessary to assume the following.

Assumption 5 (Liquidity Parameters). Assume that the parameters of the problem are all time invariant and also that $q$ has become constant with value $q^{0}$.

Then, the differential equation for $x^{r}$ can be rewritten as

$$
\begin{gathered}
-\dot{x}_{t}^{r}=-k\left(x_{t}^{r}-m\right), \quad x^{r}\left(t_{1}\right)=l^{r}, \\
k=\left(r^{\mathrm{T}}+r^{e}-r^{i}+2\left(\left(\sigma^{e}\right)^{2}+\left(\sigma^{i}\right)^{2}\right)\right)+\frac{c^{3}}{q^{0}}, \\
m=\frac{l^{r} c^{3} / q^{0}-\left(u^{1}-r^{e}-\left(\sigma^{e}\right)^{2}\right)+\left(\sigma^{e}\right)^{2}}{\left(r^{\mathrm{T}}+r^{e}-r^{i}+2\left(\left(\sigma^{e}\right)^{2}+\left(\sigma^{i}\right)^{2}\right)\right)+c^{3} / q^{0}} .
\end{gathered}
$$

Because the finite horizon is an artificial phenomenon to make the optimal stochastic control problem tractable, it is of interest to consider the long-term behavior of the INSFR reference trajectory, $x^{r}$. If the values of the parameters are such that $k>0$, then the differential equation with the terminal condition is stable. If this condition holds, then $\lim _{t \downarrow 0} q_{t}=q^{0}$ and $\lim _{t \downarrow 0} x_{t}^{r}=m$, where the down arrow prescribes to start at $t_{1}$ and to let $t$ decrease to 0 . Depending on the value of $m$, the control law at a time very far away from the terminal time becomes, then,

$$
\begin{gathered}
u_{t}^{2 *}=-\frac{\left(x_{t}-m\right) q^{0}}{c^{2}}= \begin{cases}>0, & \text { if } x_{t}<m, \\
<0, & \text { if } x_{t}>m,\end{cases} \\
\pi_{t}^{*}=-\frac{\left(x_{t}-m\right)}{x_{t}} \widetilde{C} \widetilde{r}^{j} \\
= \begin{cases}>0, & \text { if } x_{t}<m, \\
<0, & \text { if } x_{t}>m, \text { if } \pi^{*}<0 \text { then set } \pi^{*}=0 .\end{cases}
\end{gathered}
$$

The interpretation for the two cases follows below.

Case $1\left(x_{t}>m\right)$. Then, the INSFR $x$ is too high. This is penalized by the cost function; hence, the control law prescribes not to invest in risky assets. The payback advice is due to the quadratic cost function which was selected to make the solution analytically tractable. An increase in the liquidity provisioning will increase net cash outflow that, in turn, will lower the INSFR.

Case $2\left(x_{t}<m\right)$. The INSFR $x$ is too low. The cost function penalizes, and the control law prescribes to invest more in risky assets. In this case, more funds will be available and credit risk on the balance sheet will decrease. Thus, higher valued required stable fundings can be issued. Also, banks should hold less required stable fundings to decrease available stable funding which will lead in the long run to higher INSFRs.

\section{Conclusions and Future Directions}

In this paper we provide a framework for liquidity management in the banks. In actual sense, we provide a description for the inverse net stable funding ratio dynamics which promote the resilience over a longer time horizon by creating additional incentives with more stable funding sources. Also, the paper makes a clear connection between liquidity and financial crises in a numerical-quantitative frameworks (compare with Section 2). In addition, we derive a stochastic model for INSFR dynamics that depends mainly on required stable funding available stable funding as well as the liquidity provisioning rate (see Question 3). Furthermore, we obtained an analytic solution to an optimal bank INSFR problem with a quadratic objective function (refer to Question 3). In principle, this solution can assist in managing INSFRs. Here, liquidity provisioning and bank asset allocation are expressed in terms of a reference process. To our knowledge such processes have not been considered for INSFRs before. Furthermore, we also provide a numerical example in order to describe the interplay between the amount of net stable funding and liquidity demands. Specific open questions that arise out of the discussion in Section 4 are given below. The INSFR has some limitations regarding the characterization of banks' liquidity positions. Therefore, complementary Basel III ratios such as the net stable funding ratio (NSFR) should be considered for a more complete analysis. This should take the structure of the short-term assets and liabilities 
of residual maturities into account. Further questions that require investigation include the following.

(1) What is the value of the variable $m$ compared with the variable $l^{r}$ which is used in the running cost and in the terminal cost?

(2) Is $m$ higher or lower than $l^{r}$ ?

Note that from the formula of $m$ follows that

$$
m=\frac{l^{r} c^{3} / q^{0}-\left(u^{1}-r^{e}-\left(\sigma^{e}\right)^{2}\right)+\left(\sigma^{e}\right)^{2}}{\left(r^{\mathrm{T}}+r^{e}-r^{i}+2\left(\left(\sigma^{e}\right)^{2}+\left(\sigma^{i}\right)^{2}\right)\right)+c^{3} / q^{0}} .
$$

An expression for the difference $m-l^{r}$ is not obvious and depends on many parameters of the problem as it should.

There are several other directions in which the results obtained in this paper can be possibly extended. These include addressing further risk issues as well as improvements in the INSFR modeling procedure. In this regard, instead of using a continuous-time stochastic model in order to solve an optimal bank INSFR problem, we would like to construct a more sophisticated model with jump-diffusion processes (see, e.g., [30]). Also, a study of information asymmetry during the GFC should be interesting.

We have already made several contributions in support of the endeavors outlined in the previous paragraph. For instance, our paper [24] deals with issues related to liquidity risk and the GFC. Furthermore, we started dealing with jump diffusion processes in the book chapter [30]. Also, the role of information asymmetry in a subprime context is related to the main hypothesis of the book [22].

\section{Appendices}

\section{More About Bank INSFRs}

In this section, we provide more information about required stable funding and available stable funding.

\section{A. Required Stable Funding}

In this subsection, we discuss the stock of high-quality required stable funding constituted by cash, $\mathrm{CB}$ reserves, marketable securities, and government/CB bank debt issued.

The first component of stock of high-quality required stable funding is cash, that is, it made up of banknotes and coins. According to [3], a CB reserve should be able to be drawn down in times of stress. In this regard, local supervisors should discuss and agree with the relevant $\mathrm{CB}$ the extent to which $\mathrm{CB}$ reserves should count toward the stock of required stable funding.

Marketable securities represent claims on or claims guaranteed by sovereigns, CBs, noncentral government public sector entities (PSEs), the Bank for International Settlements (BIS), the International Monetary Fund (IMF), the European Commission (EC), or multilateral development banks. This is conditional on all the following criteria being met. These claims are assigned a $0 \%$ risk weight under the Basel II Standardized Approach. Also, deep repo markets should exist for these securities and that they are not issued by banks or other financial service entities.

Another category of stock of high-quality required stable funding refers to government/CB bank debt issued in domestic currencies by the country in which the liquidity risk is being taken by the bank's home country (see, e.g., $[3,4]$ ).

\section{B. Available Stable Funding}

Cash outflows are constituted by retail deposits, unsecured wholesale funding, secured funding, and additional liabilities (see, e.g., [3]). The latter category includes requirements about liabilities involving derivative collateral calls related to a downgrade of up to 3 notches, market valuation changes on derivatives transactions, valuation changes on posted noncash or nonhigh quality sovereign debt collateral securing derivative transactions, asset backed commercial paper $(\mathrm{ABCP})$, special investment vehicles (SIVs), conduits, and special purpose vehicles (SPVs) as well as the currently undrawn portion of committed credit and liquidity facilities.

Cash inflows are made up of amounts receivable from retail counterparties, amounts receivable from wholesale counterparties, and amounts receivable in respect of repo and reverse repo transactions backed by illiquid assets and securities lending/borrowing transactions, where illiquid assets are borrowed as well as other cash inflows.

According to [3], net cash inflows is defined as cumulative expected cash outflows minus cumulative expected cash inflows arising in the specified stress scenario in the time period under consideration. This is the net cumulative liquidity mismatch position under the stress scenario measured at the test horizon. Cumulative expected cash outflows are calculated by multiplying outstanding balances of various categories or types of liabilities by assumed percentages that are expected to roll-off and by multiplying specified drawdown amounts to various off-balance sheet commitments. Cumulative expected cash inflows are calculated by multiplying amounts receivable by a percentage that reflects the expected inflow under the stress scenario.

\section{References}

[1] Basel Committee on Banking Supervision, Progress Report on Basel III Implementation, Bank for International Settlements (BIS), Basel, Switzerland, 2011.

[2] Basel Committee on Banking Supervision, Basel III: A Global Regulatory Framework for More Resilient Banks and Banking Systems-Revised Version, Bank for International Settlements (BIS), Basel, Switzerland, 2011.

[3] Basel Committee on Banking Supervision, Basel III: International Framework for Liquidity Risk Measurement, Standards and Monitoring, Bank for International Settlements (BIS), Basel, Switzerland, 2010.

[4] Basel Committee on Banking Supervision, Principles for Sound Liquidity Risk Management and Supervision, Bank for International Settlements (BIS), Basel, Switzerland, 2008.

[5] H. Almeida and M. Campello, "Financial constraints, asset tangibility, and corporate investment," The Review of Financial Studies, vol. 20, no. 5, pp. 1429-1460, 2007. 
[6] D. Gromb and D. Vayonos, A Model of Financial Market Liquidity Based on Intermediary Capital, London School of Economics, CEPR and NBER, London, UK, 2009.

[7] S. W. Schmitz, "The impact of the Basel III liquidity standards on the implementation of monetary policy," 2011, http:// papers.ssrn.com/sol3/papers.cfm?abstract_id=1869810.

[8] R. M. Lastra and G. Wood, "The crisis of 2007 till 2009: nature, causes and reactions," Journal of International Economic Law, vol. 13, no. 3, pp. 531-550, 2009.

[9] Basel Committee on Banking Supervision (BCBS), Consultative Document, International Framework for Liquidity Risk Measurement, Standards and Monitoring, Bank for International Settlements (BIS) Publications, 2009, http://www.bis.org/ $\mathrm{publ} / \mathrm{bcbs} 165 . \mathrm{htm}$.

[10] Basel Committee on Banking Supervision (BCBS), Basel III: International Framework for Liquidity Risk Measurement, Standards and Monitoring, Bank for International Settlements (BIS) Publications, 2010, http://www.bis.org/publ/bcbs188.htm.

[11] Basel Committee on Banking Supervision (BCBS), Principles for Sound Liquidity Risk Management and Supervision, Bank for International Settlements (BIS) Publications, 2008, http://www.bis.org/publ/bcbs144.htm.

[12] H. Hannoun, Towards a Global Financial Stability Framework, Bank for International Settlements, 2010, http://www.bis.org/ speeches/sp100303.htm.

[13] Basel Committee on Banking Supervision (BCBS), Consultative Document, Strengthening the Resilience of the Banking System, Bank for International Settlements (BIS) Publications, 2009, http://www.bis.org/publ/bcbs164.htm.

[14] G. Calice, J. Chen, and J. Williams, "Liquidity interactions in credit markets: an analysis of the eurozone sovereign debt crisis," Electronic Journal of Economics. In press, http://papers.ssrn .com/sol3/papers.cfm?ab-stractid=1776425.

[15] N. Isaac, "EU bailouts fail to keep European Sovereign debt markets afloat," April 2011, http://www.elliottwave.com/.

[16] A. Locarno, The Macroeconomic Impact of Basel III on the Italian Economy, Occasional Paper no. 88, Questioni di Economia e Finanza, 2011, http://papers.ssrn.com/sol3/papers.cfm? abstract_id $=1849870$.

[17] MAG (Macroeconomic Assessment Group), Assessing the Macroeconomic Impact of the Transition to Stronger Capital and Liquidity Requirements Final Report, The Financial Stability Board and the BCBS, 2010.

[18] Basel Committee on Banking Supervision (BCBS), An Assessment of the Long-Term Economic Impact of Stronger Capital and Liquidity Requirements, Bank for International Settlements (BIS) Publications, 2010, http://www.bis.org/publ/bcbs175.htm.

[19] C. Schmieder, H. Hesse, B. Neudorfer, C. Puhr, and S. W. Schmitz, "Next generation system-wide liquidity stress testing," IMF Working Paper WP/12/3, Monetary and Capital Markets Department, 2012.

[20] M. Ojo, "Preparing for Basel IV—-why liquidity risks still present a challenge to regulators in prudential supervision," December 2010, http://papers.ssrn.com/sol3/papers.cfm?abstract_id= 1729057.

[21] Basel Committee on Banking Supervision, Basel III: A Global Regulatory Framework for More Resilient Banks and Banking Systems-Revised Version, Bank for International Settlements (BIS), Basel, Switzerland, 2011.

[22] M. A. Petersen, M. C. Senosi, and J. Mukuddem-Petersen, Subprime Mortgage Models, Nova, New York, NY, USA, 2012.
[23] G. B. Gorton, The Panic of 2007, Working Paper no. 0824, Yale ICF, 2008, http://papers.ssrn.com/sol3/papers.cfm? abstract_id $=1255362$.

[24] M. A. Petersen, B. De Waal, J. Mukuddem-Petersen, and M. P. Mulaudzi, "Subprime mortgage funding and liquidity risk," Quantitative Finance. In press.

[25] Y. Demyanyk and O. van Hemert, "Understanding the subprime mortgage crisis," Review of Financial Studies, vol. 24, no. 6, pp. 1848-1880, 2011.

[26] D. P. Bertsekas, Dynamic Proggramming and Optimal Control, Volumes I and II, Athena Scientific, 2007.

[27] E. D. Sontag, Mathematical Control Theory: Deterministic Finite Dimensional Systems, vol. 6, Springer, New York, NY, USA, 2nd edition, 1998.

[28] W. Kratz, Quadratic Functionals in Variational Analysis and Control Theory, vol. 6 of Mathematical Topics, Akademie, Berlin, Germany, 1995.

[29] E. A. Coddington and R. Carlson, Linear Ordinary Differential Equations, Society for Industrial and Applied Mathematics (SIAM), Philadelphia, Pa, USA, 1997.

[30] F. Gideon, M. A. Petersen, J. Mukuddem-Petersen, and B. De Waal, "Bank liquidity and the global financial crisis," Journal of Applied Mathematics, vol. 2012, Article ID 743656, 27 pages, 2012. 


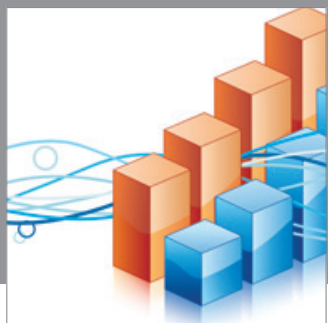

Advances in

Operations Research

mansans

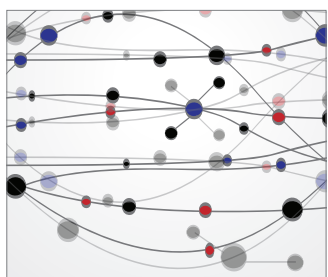

The Scientific World Journal
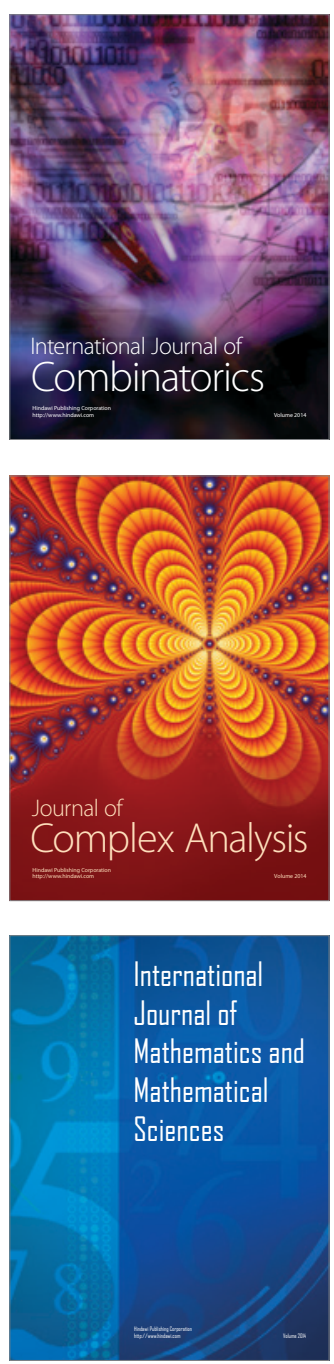
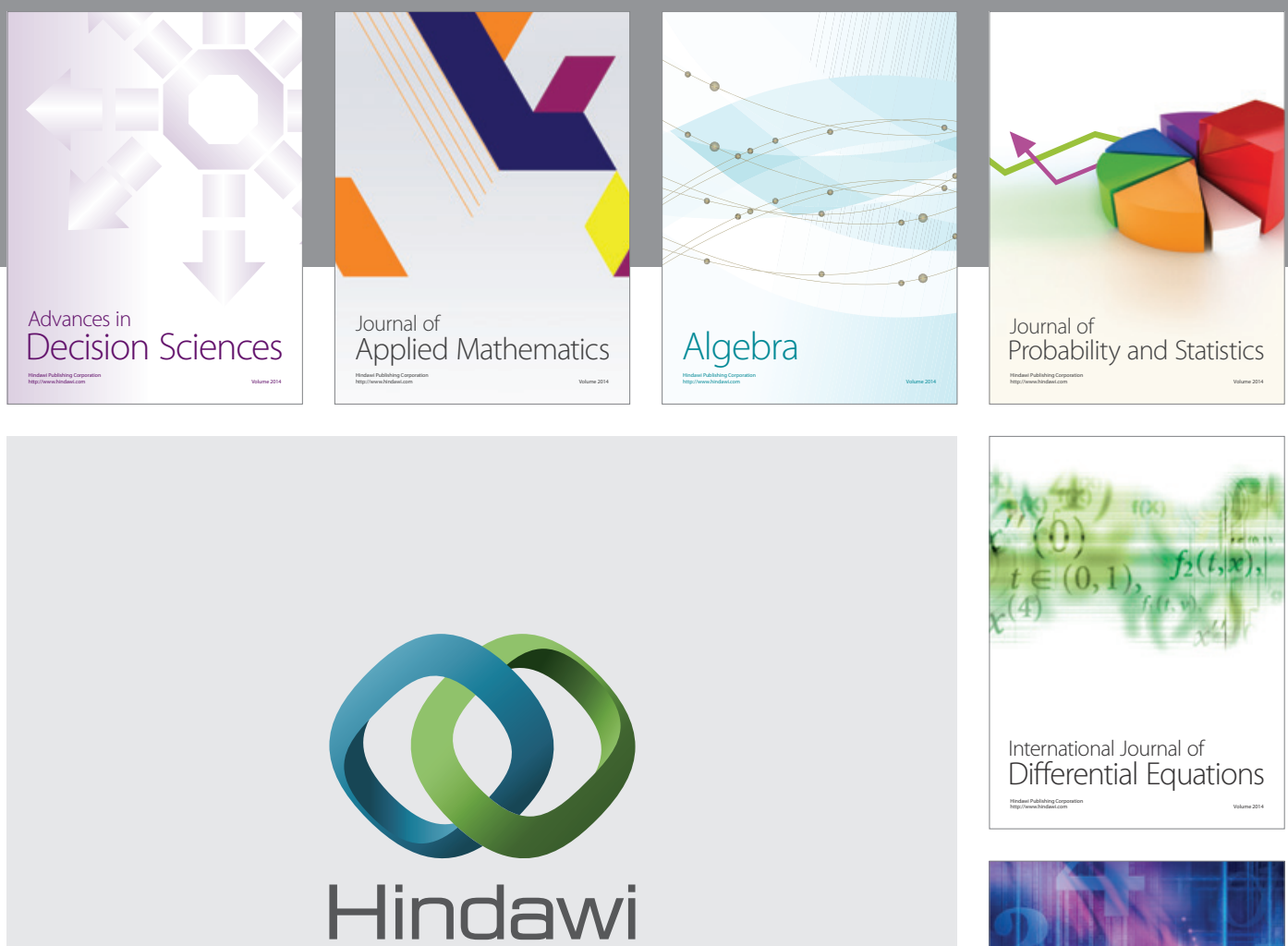

Submit your manuscripts at http://www.hindawi.com
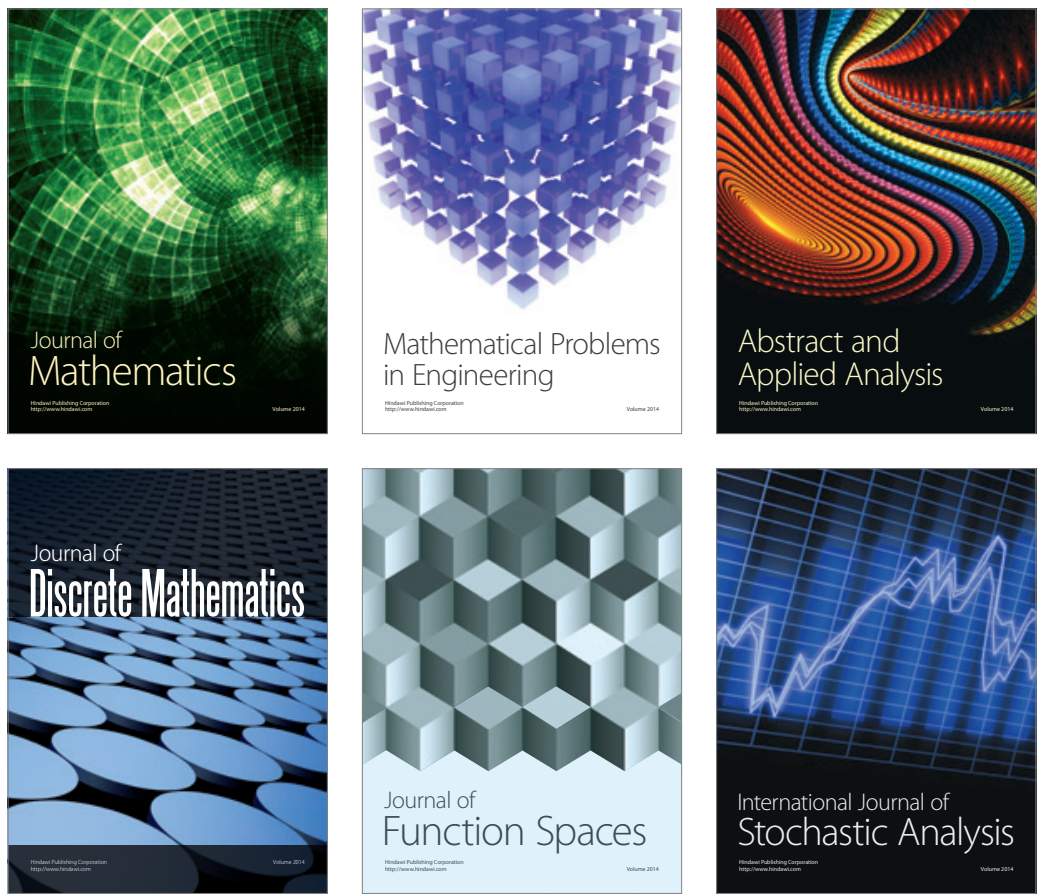

Journal of

Function Spaces

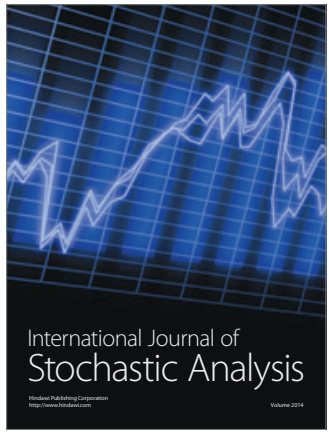

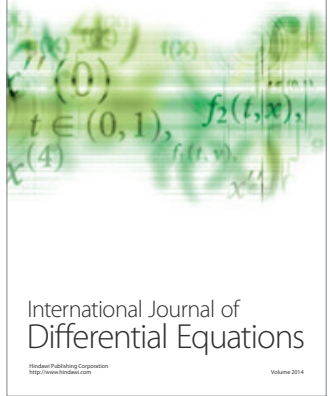
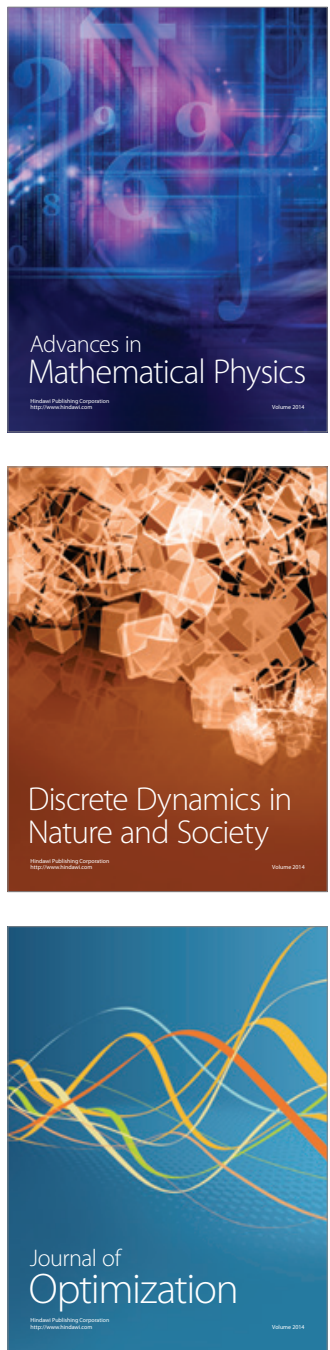